\title{
Development of Solar Concentrator studded with Optical Fiber for Daylighting
}

\author{
${ }^{1}$ Amit Kumar Sharma, ${ }^{2}$ Raju Narwade, ${ }^{3}$ Karthik Nagarajan, ${ }^{4}$ Saurabh Sirsikar \\ ${ }^{1}$ M.E. Student, ${ }^{2,3,4}$ Professor, Civil Engineering Department, Pillai HOC College of Engineering and Technology, Rasayani, \\ Maharashtra, India. ${ }^{1}$ amd4pro@gmail.com, ${ }^{2}$ rnarwade@mes.ac.in, ${ }^{3}$ knagarajan@mes.ac.in, ${ }^{4}$ saurabhsirsikar@mes.ac.in.
}

DOI: 10.29322/IJSRP.11.11.2021.p11966

http://dx.doi.org/10.29322/IJSRP.11.11.2021.p11966

\begin{abstract}
Over the years there has been an increase in the energy consumption pattern which has given rise to various environmental issues. Around $20 \%$ of the energy is used for lighting purpose and conferring to a U.S. Energy Information Administration 2007 \& International Energy Agencies 2006 report lighting amounts for 7\% of the $\mathrm{CO}_{2}$ emissions globally and releases around 1900 metric tons of carbon dioxide $\left(\mathrm{CO}_{2}\right)$ into the atmosphere. Due to this issue an environment friendly solution which utilizes renewable form of energy so that even actions like lighting the buildings could be sustainable. About 50-80\% of energy consumption for lighting can be saved through designing an efficient daylighting system to light the interior spaces in the buildings, which would provide various physiological and psychological benefits for the wellbeing of human beings. In this study a daylighting system is designed on the Cassegrain principle and evaluated through software's and experimental setup. A model of the daylighting system is constructed using simple and low cost materials, easily available and reliable. Maximum solar radiation point was ascertained by studying sun path diagrams. The model was tested for its lux intensity and temperature on 5 sunny days over a period of 6 hours. The daylighting system provides a lux intensity of above 1400 at its peak hour and 323 lux at its minimum through a bundle of 209 individual optical fibers enclosed in a circular pipe of $3 / 4$ inch in diameter. The temperature attained was $60^{\circ} \mathrm{C}$ and $50^{\circ} \mathrm{C}$ which were well within the operating temperature limits of the optical fiber.
\end{abstract}

Keywords - Cassegrain reflector, Daylighting system, Fiber optic concentrator, lux intensity, Non-imaging concentrator, Total internal reflection

\section{INTRODUCTION}

\subsection{SOLAR POTENTIAL OF INDIA}

Energy is in everything - it is often defined as "the ability to do work [1]. Energy resources are present in two types and they are as follows.

- Renewable (a source that can be easily refilled)

- Nonrenewable (a source that cannot be easily refilled) Solar energy is renewable power source which is an inexpensive, clean and harness able resource which could be harnessed anywhere in the world. Around $1000 \mathrm{~W} / \mathrm{m} 2$ density energy is received on a clear day at Earth surface which would be perpendicular to the incoming sunrays and would be at sea level [2]. Hence, a point on any location on the earth where the sunlight can reach becomes a potential point to harness the solar energy coming from the sun. India geographical extents, i.e., latitude and longitude extends from $8^{\circ} 4^{\prime} \mathrm{N}$ to $37^{\circ} 6^{\prime} \mathrm{N} 68^{\circ} 7^{\prime} \mathrm{E}$ to $97^{\circ} 25^{\prime} \mathrm{E}$ which is shown in Fig. 1.

India geographical extents it is situated very close to the equator, also the tropic of cancer line which is an imaginary line inclined at an angle of 23.50 degrees North from the equator passes through eight states in India that indicates it lies in the luminous regions of the world. Due to this India receives around 300 days of daylight of the 365 days in a year that makes the country a favorable place for solar exploitation [3]. Fig. 2 shows a map of India indicating the various parts of the country with their solar radiation levels.

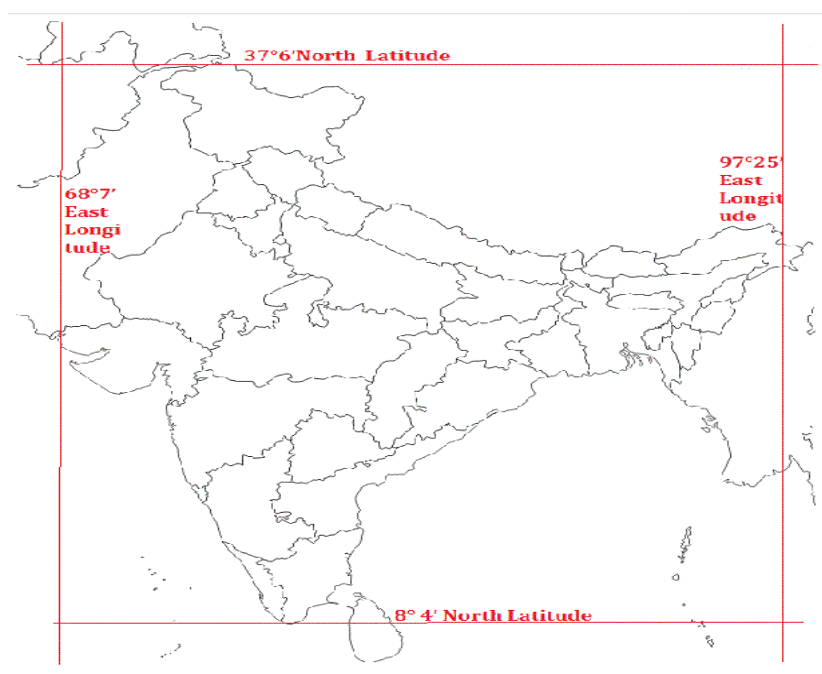

Fig 1. Latitudinal and Longitudinal Map of India [5]

Rajasthan, Northern Gujrat and some portions of Ladakh area, some portions of Andhra Pradesh, Maharashtra, Madhya Pradesh get a good amount of solar radiation with 
respect to several parts of the world. The technical potential of exploiting the solar energy and generating a good amount of energy may surpass the existing energy requirement which looks promising in the near future [4].
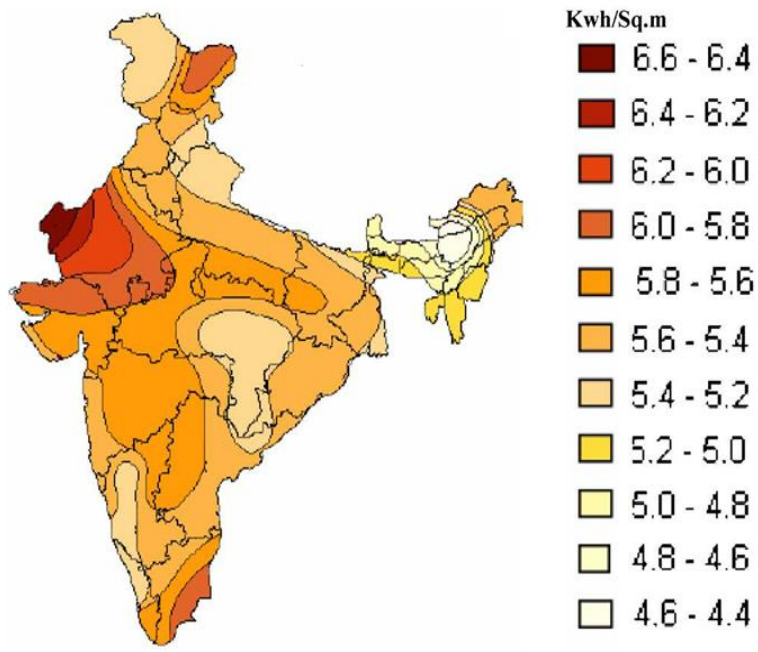

Fig 2. Solar radiation on India [6]

\subsection{ELECTRICITY CONSUMPTION IN INDIA}

In the current years India is recognized as the third largest economy of the world which is continuously developing and increasing its position continuously. The residential sector and commercial sector amounts to $30 \%$ ( $22 \%$ residential and $8 \%$ commercial) of the overall electricity demands and a $8 \%$ growth is can be seen in this sector annually [7]. According to NMEEE report 2009 prediction, the annual consumption of the residential and commercial sector could increase from $19200 \mathrm{KWh}$ to $89,823 \mathrm{KWh}$ between 2005 to 2030.In Fig. 3 energy consumption and its distribution in residential sector is shown, it can be seen from the distribution that lighting and fans constitute a majority portion i.e. $62 \%$ in the distribution [8].

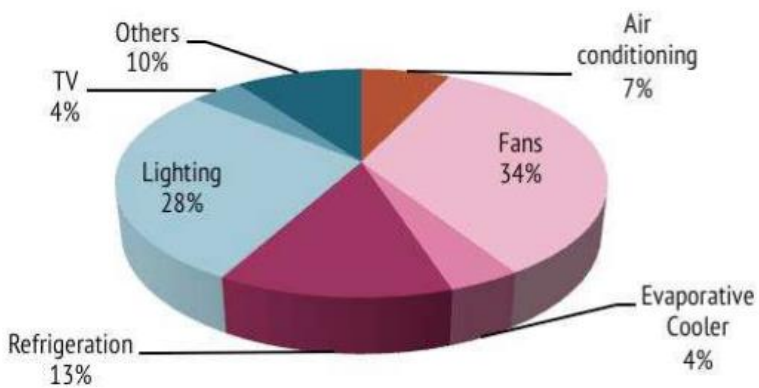

Fig 3. Energy Consumption in Residential Sector [9]

Almost one fifth of the overall electricity produced globally comprises of lighting sector. The total electricity demand of building lighting far exceeds the production capacity of electricity through hydro power plants and natural gas. The electricity consumed for lighting purpose in IEA member countries is $50 \%$ and in the upcoming years this statistics is likely to change due to rapid growth in consumption of electricity for lighting would be seen in non-IEA nations [10].

\subsection{PROBLEM STATEMENT}

Even in the hours of daylight, lighting comprises of a major chunk in the energy consumption of a building, which releases a large amount of $\mathrm{CO}_{2}$ in the atmosphere [11]. Lighting produces around $1900 \mathrm{Mt}$. of $\mathrm{CO}_{2}$ which roughly accounts for $7 \%$ of the total $\mathrm{CO}_{2}$ emissions generated through burning fossil fuels globally for power generation [12,13]. Above $20 \%$ of the electricity is consumed in lighting the buildings globally as stated by The International Agency (IEA) [14].

In the year 2017 the global median average of carbon dioxide $\left(\mathrm{CO}_{2}\right)$ was $405.0 \mathrm{ppm}$ (parts per million), this has been the highest peak achieved in this decade since the last 800,000 years which can be seen in Fig. 4. These figures were reported in a study recently conducted by NOAA NCEI Paleoclimatology Program.

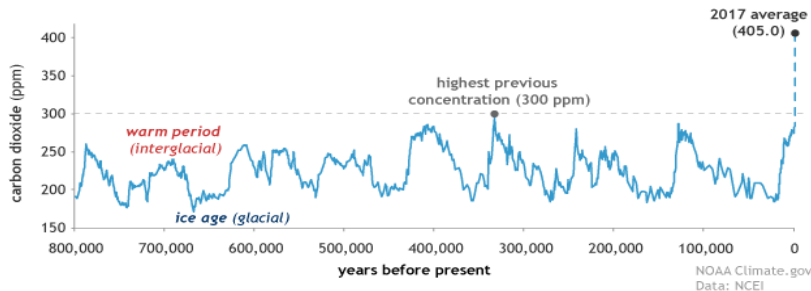

Fig 4. Atmospheric carbon dioxide concentrations in parts

per million (ppm) for the past 800,000 years [15]

The typical conversion efficiency of solar energy to electricity and then to light is less than $1 \%$ and in this process undesirable heat is produced which raises the room temperature which is shown in Fig, 5, on the other hand direct use of sunlight could increase the efficiency by $50 \%$ which is shown in Fig. 6. In addition, in the conversion process of electrical energy to light energy losses are incurred which is given out from the system in the form of heat.

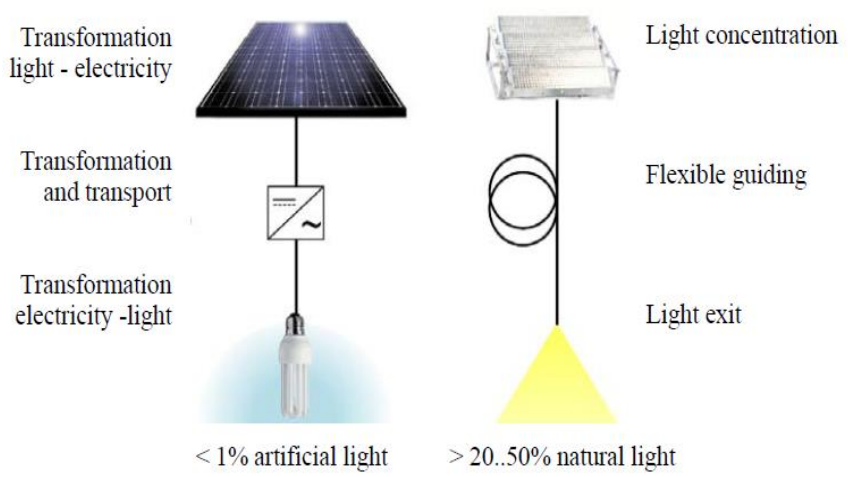

Fig 5. Comparison electrical (left) and direct (ríght) illumination path [16]

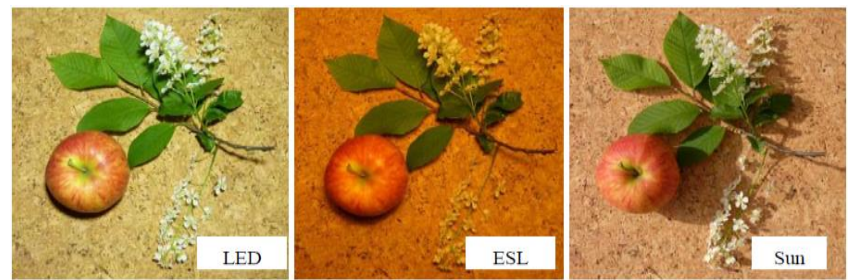

Fig 6. Different colour rendering using different light sources [16].

The light emitted from the traditional lights are not close enough to the visible spectrum and are of different colors due to the impurities present in them hence, they strain the eyes 
and do not reveal the true color of the object which is explained in the Figure 6. Also there is a decrease in the luminous intensity of the traditional lighting system over their life cycle which can be termed as dimming. At the end of their life cycle disposing of the traditional lights can pose a problem to the environment as these lights contains heavy metals like lead, nickel and copper which can cause allergic reaction upon exposure and can accumulate in rivers and lakes which could lead to poisoning of aquatic life [17].

\subsection{RESEARCH CONTRIBUTION \& OBJECTIVE}

This investigation would help to assess the feasibility and potential of a daylighting system coupled with fiber optic and non-imaging concentrator in the study area. The basic approach behind this idea is to concentrate and channel the sunlight through the fiber optical cable effectively. As India is a developing country and derives its energy through nonrenewable form of energy for lighting purposes this work could potentially save this energy, which could be utilized for other purposes. As this work utilizes renewable form of energy, it wouldn't produce any greenhouse gases in the process which would in turn save on the emission of greenhouse gases and would make earn the building a green status and would be sustainable for the masses.

The main objectives of this research work consist of developing a cost effective passive daylighting system. The study focuses on to assess the feasibility of the daylighting system at the study area, investigate the luminous intensity it would provide at the outer end of the fiber cable and to compare this output with the luminous intensity emitted by the traditional lighting system. The temperature at the outer end and inner end of optical fiber is measured to check and keep the temperature under working conditions.

\section{LITERATURE REVIEW}

Following section briefs about the various research works referred for this study. There have been many researches carried out in the past to ascertain the feasibility of the daylighting system and its effectiveness in lighting the interiors of the buildings with the help of optical fibers. KokKeong Chong et al. (2017) proposed an innovative two-stage reflective non-imaging dish concentrator (NIDC) which involved two mirrors i.e primary and secondary mirrors focussing the sunrays onto a high acceptance angle optical fibres placed at the centre of the concentrator. Through this optical fibres the light could be guided into the building internal areas. The daylighting system was built by designing the various components and was evaluated under normal conditions. The prototype reflective area was $0.2 \mathrm{~m}^{2}$ which under a solar irradiance of $1000 \mathrm{~W} / \mathrm{m}^{2}$, could give a lux intensity of 647.94 lux and was capable enough to brighten an area of $6.3 \mathrm{~m}^{2}$ in a office buliding. On comparison with the standard average illumination of 500 lux it could brighten an area of $8.164 \mathrm{~m}^{2}$ [11]. Lei Li et al. (2018) in this study a daylighting system was designed with a fresnel lens coupled along with the optical fiber which could concentrate the sunlight into the optical fibers. The primary purpose of this work was to test the possibility of using a Fresnel lens with a large aperture in the system. They developed a model and performed their test to verify the feasibility of the system. The experiment was conducted on $26^{\text {th }}$ July 2017 between 9 AM to 3 PM under a direct normal irradiation of above $800 \mathrm{~W} / \mathrm{m}^{2}$ and the temperature was kept normal at $28^{\circ} \mathrm{C}$. During this period the PMMA fiber bundle's spectrum output and the lighting effect were measured which gave a stable spectrum continuously for 6 hours. Achieving a stable spectrum indicated that during the high flux transmission the bundles remained unharmed over the period of exposure. From this experiment it was clear that with the combination of both heat protection measures, temperatures in the fiber bundles could be regulated and kept at safe level during its application as a daylighting system [20]. The Universiti Tunku Abdul Rahman which bears the longitude and latitude location of $101.79 \& 3.04$, a model of 2S-NISC was placed over the roof of this building for testing under a normal irradiance of $1000 \mathrm{~W} / \mathrm{m}^{2}$. During the testing, results indicated that the 2 S-NISC model having a collective area of $0.2 \mathrm{~m}^{2}$ and consisting of 314 optical fibers could illuminate $7.4 \mathrm{~m}^{2}$ area of a room with an average illuminance of 500 lux (3705.2 lumen). This interior illuminance generated by 2 S-NISC with a input power of 160 Watts could correspond to 32 LEDs with a combined electrical power rating of $35.84 \mathrm{~W}$. A economic analysis performed for the 2S-NISC daylighting system having a power conversion efficiency of $22 \%$ and area coverage of $4 \mathrm{~m}^{2}$ was valued at USD 1231.20. The total payback period of 6.5 years was calculated by keeping the rate of interest at $4 \%$ and considering $2 \%$ as the rate of fuel inflation, which seemed to be fair enough as the system could be used for upto 15 years Kok-Keong Chong et al. (2017) [21].

Ravi Gorthala, Meg Tidd, and Sean Lawless (2017) This paper deals with a novel approach towards using a fiber optics in a mobile solar lighting system. The main purpose of this study is designing and developing a solar concentrator having two stages of optics. Due to low accuracy tracking and higher tolerance to sun angle two stage optics have an added advantage over an active solar tracking. Optimal geometries of the secondary lenses were calculated using ray tracing tool and different geometrical shapes were simulated such as compound parabolic (CPC) and conical concentrator, compound elliptical concentrator (CEC) and conical etc. Out of the different geometrical shapes analyzed the best combination was of compound elliptical concentrator (CEC) and conical which yielded better results with respect to total light output and peak illumination. Based on the designs a model of secondary lens was made-up from acrylic and optical silicones. The measured lumen output of the acrylic lens gave good results than the silicone lenses which was measured from a portable integrating sphere radiometer. For five months spanning from spring to summer the system was tested and was placed on a rooftop to receive sufficient amount of sunlight from $8 \mathrm{AM}$ to $6 \mathrm{PM}$. The efficiency of the measured output through the acrylic lens was $66 \%$ nearing the prediction given by the photopia software which was at $69 \%$. [22].

Yuexia Lv et al. (2017) made an attempt towards designing a dual system consisting of fiber optic daylighting coupled with solar PV lighting panels in house hold purposes. This system is divided into three parts i.e light collecting, control system, light guiding and a light diffusing subsystem consisting of fiber optic. To make up the light collection subsystem , 9 fresnel lens of identical specifications was fixed in order to utilize it as a solar concentrator. In this way the solar rays focus could be shifted from a larger area to a relatively smaller area i.e. receiver unit consisting of polymethyl methacrylate (PMMA) optical fibers which would deliver and distribute the light into the interiors of building. Polymethyl methacrylate (PMMA) optical fibers 
are preferred due to its higher light transmittance, highly resistant to ultraviolet irradiation, lower dispersion and greater stiffness. The diffuser is made up of optical fibers, shell, panel, base board and diffusing lens. A systematically arranged solar tracker, power generation control module and a control module forms the control system. Preliminary analysis proved to provide a stable illumination in the interior spaces, also the hybrid lighting system could provide with an average 9 hours of continuous electricity generation. When tested in room area of $5 \mathrm{~m}^{2}$ it considerably reduced the release of $158.2 \mathrm{~kg}$ of $\mathrm{CO}_{2}$ around the year [23]. Georgios E. Arnaoutakis et al. (2013) in this study it was shown that Optical fibers have an added advantage of being included in the solar concentrator systems by transporting the light into distant places with same illumination level and direct conversion of solar energy into light. In this study the critical parameters required for combining the rays received from the sun into the optical fibers were determined for controlling the efficiency of the system. A ray tracing simulation was developed and experimented on the two-stage solar concentrator consisting of optical fibers. Analysis of focal ratio with respect to acceptance angle of primary and secondary concentrators enhanced the basis of this study in comparing the coupling efficiency. Spectral dependence was studied and obtained in the form of wavelength function which described the solar concentration on the system. Around 2000 suns $\left(1\right.$ sun $\left.=1 \mathrm{KW} / \mathrm{m}^{2}\right)$ concentration was achieved by narrowing the acceptance angle, adjusting and controlling the chromatic deviations of the primary concentrators. The numerical aperture value of optical fiber was retained at $50 \%$ with respect to the angle of secondary concentrator, as a small amount of deviation would hamper in achieving the maximum performance. This study laid emphasis on enhancing the parameters and coupling efficiency in order to effectively commercialize the optical fiber usage in solar energy applications [24]. H. Poisel et al. (2011 This paper presents a basic method to concentrate and direct the sunlight to distant places inside the building. They performed their experiments at IIT chennai campus due to availability of abundant sunlight in the regions near the equator. Their design consisted of a systematic arrangement of injection moulded concentrators and fiber optical bundles enclosed in a discrete panel. Adjustments had to be made throughout the day with respect to suns position as the daylighting system was passive in nature. The sunrays were gathered together through 224 lenses fitted in four panels and was conveyed by 8 optical fiber bundles through which the light was dispersed to various places through hybrid luminaires located two floors underneath in a cabinet. The Cabinet consisted of different systems that were included to measure the temporal and spectral distribution along with the overall power quantity. Climatic parameters was also taken into consideration as it could cause deviation of efficiency in discrete concentrators. Their result yielded that their design was capable to distribute the sunlight efficiently in the room and could prevent unnecessary loss of energy, as well as it could provide the luminous intensity which could improve the well being of humans [16].

Han et al. (2013) in this study it was shown that the use of active daylight uses sunlight quite belligerently and encourages suppleness by illuminating the interiors of the building. Their proposed model of daylighting system consisted of optical fibers coupled with solar tracking technology, which were capable of tracking the sunrays along the sun path to provide an optimal supply of light to illuminate the building interiors. This paper showcases a well-designed daylighting system made up of dish concentrators with a dual axis solar tracking mechanism and light directors consisting of fiber optic bundles formed in a cable, which could be used to fulfil the purpose of sustainable lighting. The daylighting system was modelled in various simulation softwares out of which the Photopia was able to provide the pertinent photometric data i.e. CDCs and candela power distribution curves through creating a computer generated luminaire. To evaluate, different models were created and validated by running a successions of test that were carried out in a test compartment. Dimming control were deployed in order to assess and explore the combined possibilities of orthodox electric lighting and sunlight [25]. Jifeng song et. al. (2015) In this paper they presented a daylighting system which worked on a parallel mechanism, they designed and fabricated this system which included fiber optical cables. This whole assembly of daylighting consisted of 49 concentrating cells arranged in an orderly manner of $7 \times 7$ array. This array included 48 sunlight collecting cells with a direct focus detection mechanism which had sunposition sensors embedded in them. To track the sun a linear actuator consisting of stepper motors and roller screws drove the concentrating array in a plane parallel to the plane of the array consisting of the collecting aperture. For 8 hours of tracking the solid angle range of the concentrating cells were kept at $4 \pi / 3$ sr which would cover around $2 / 3$ of the sky. The sun position sensors consisted of photodiodes while the array consisting of fiber optical cables was shaped in a cross symbol. The high flux density that was focused on the collecting aperture was measured by the sunposition sensors which came upto a concentration level of 2500 suns. The test for photometric characteristic was performed in a lightless underpass of dimension $8.6 \mathrm{~m} \mathrm{x} 4.2$ $\mathrm{m} \times 2.3 \mathrm{~m}$ with a lux meter and spectrometer. the experimental results yielded that light transfer of $25 \%$ could be achieved with a $10 \mathrm{~m}$ long fiber optical cables. A infrared light filter was placed to filter out the excessive heat which would be produced at the collecting aperture consisting of fiber optical cables that would hamper its working efficiency. On experimental measurement of the transfer efficiency along a $10 \mathrm{~m}$ long fiber optical cable gave a $25 \%$ transfer efficiency results, also at the output end of the fiber cable a luminous efficacy of $250 \mathrm{lum} / \mathrm{W}$ was achieved. This experiment confirmed the probability of daylighting system with a corresponding mechanism and achieved efficacy of $250 \mathrm{lum} / \mathrm{W}$ which was twice that of natural light as it could efficiently filter out the infrared light [26]. M. Rahou et. al., (2016) In this paper the authors analyzed the feasibility of proficiently conveying the concentrated solar energy to a load capacity which was has been a difficult task to achieve in solar thermal applications with high temperature. They also pointed out that the solar concentrators bundled with optical fiber cable had an edge over the conventional method of heat transfer to fluid with heat exchangers. The transmission efficiency was found to be higher incase of solar concentrators coupled with optical fiber bundle over a length of $100 \mathrm{~m}$ through simulation and experiments. A point focused fresnel lens was provided to concentrate the sunlight to the individual optical fiber with a incident angle lesser than their individual fiber acceptance angle in the bundle. Spatial coherence and interference effects was neglected in this study as the spectrum band of the sunlight had a broad scope. To cover the absorption by the fiber bundle and nonideal internal reflection inside the individual fiber a ray 
tracing model that included the above mentioned criteria was prepared for simulation. In order to find the amount of radiation emission at the exit end of the fiber optic cable an integration covering all directions of their wavelength at each point was considered. From the simulation results it was estimated that about two third of the losses occurring at the entrance end of the optical fiber bundle are due to its padding material around the discrete fiber. The average transmission per meter length through the fiber bundle consisting of 15 mm diameter and 27,000 low $\mathrm{OH}$ fiber was around 52\% with a fresnel lens [27].

\section{METHODOLOGY}

This section divulges about studying the area for its solar lighting potential, designing and construction of the prototype along with materials and its properties as well as the methodology adopted for the investigation. This section gives a brief idea about the various designing aspects considered while designing and selection of the materials for building the daylighting system. Further, a brief description about the different instruments involved for testing this research work has been given and a detail procedure followed for testing the luminous intensity and temperature are explained in a step by step process. The methodology followed in this research work is shown in a flow chart format in Fig. 7.

\subsection{STUDY AREA}

The area selected for this research work is Pillai HOC College of engineering, situated in Rasayani that falls under Raigad district of Navi Mumbai. It is an educational institution spread over an area of 14 acre with more than $3,00,000$ sq. $\mathrm{ft}$ of built up area as shown in Fig. 8. Pillai HOC college of engineering falls between latitude $18.8932^{\circ} \mathrm{N}$ and longitude $73.1764^{\circ} \mathrm{E}$ respectively. It is situated at 18.37 meters above mean sea level with a mean humidity of $56 \%$. Pillai HOC campus is a $U$ shaped construction of $\mathrm{G}+9$ floors, it has a garden and a canteen situated in the empty part of the $\mathrm{U}$ formation. Being massive in height the area in the empty U space, it blocks the initial direct natural sunlight before noon. The $U$ shaped area receives direct solar radiation only intended for a small period of time i.e. from $12 \mathrm{AM}$ to 2.30 PM after which again the sunlight is blocked for rest of the day. Hence to get optimal receiving point of solar radiation a point in the backyard of the campus building was selected which is shown in Fig. 9. As this point is located in front of a ground with no tall building structure or trees in the immediate vicinity it would be considered as a best option as it would be free from shadow formation by these structures.

\subsection{DESIGN OF DAYLIGHTING SYSTEM}

A daylighting system as a whole is made up of two individual parts i.e. solar concentrator and light guiding system. The solar concentrator works as the essential element of the system which collects the direct sunlight and focuses it onto the light guiding system. The light guiding system receives this focused sunlight coming onto it and channels it through optical fiber bundles.

The design of the individual systems are based on two concepts i.e. Double reflection and Total Internal reflection ( TIR) which forms the backbone of this daylighting system design. The whole solar assembly is intended to follow the concept and design of cassegrain reflector and uses double reflection principle to focus the area with double the reflection.

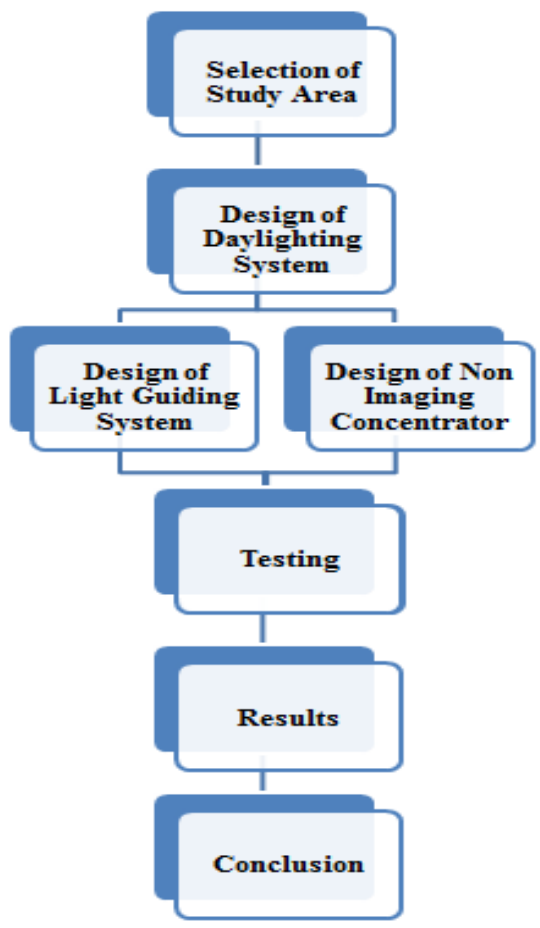

Fig 7. Flow chart of methodology

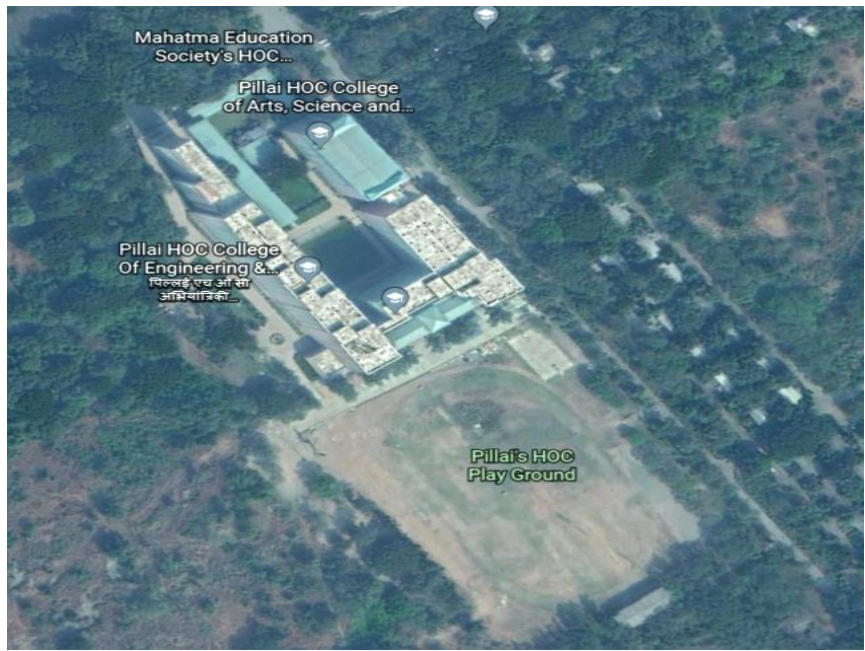

Fig 8. Pillai HOC Campus, Rasayani (19) 


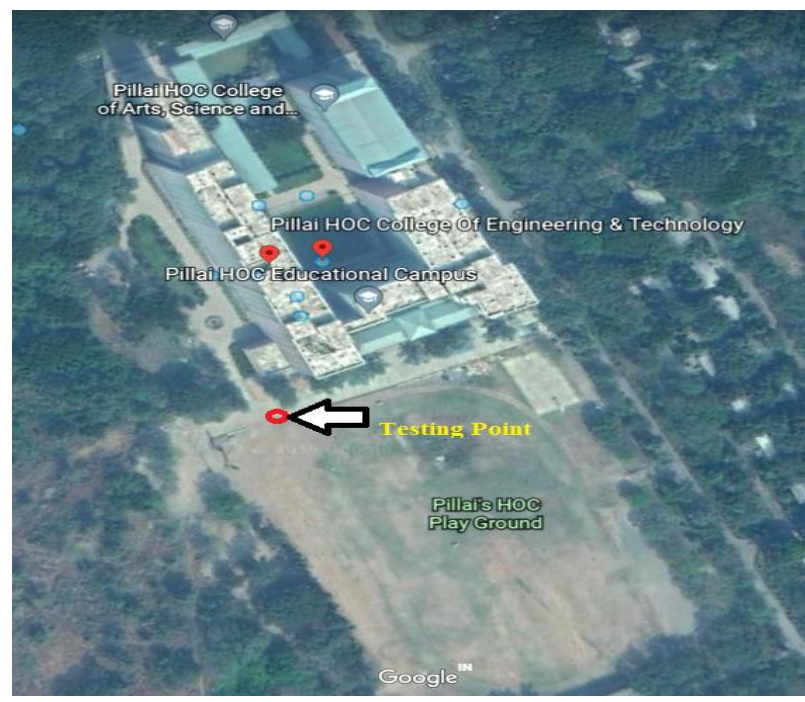

Fig 9. Testing point selected at Pillai HOC Campus,

Rasayani (19)

This concept is used in modern day reflecting telescopes which doubles the reflection at a point using two reflectors and is shown in Fig. 10.

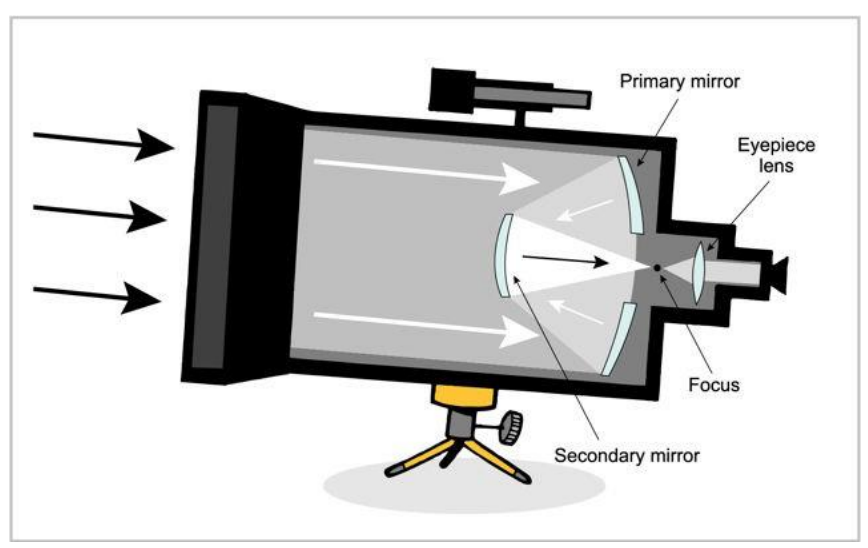

Fig 10. Light path in a Cassegrain reflecting telescope (18)

The light guiding system consist of PMMA end glow plastic optical fiber bundles which transfers the oncoming direct sunlight through it on the principle of total internal reflection. Total internal reflection is a phenomena in which all the reflection from the incident light is reflected back from its boundaries which is shown in Fig. 11. In order for TIR to happen certain conditions have to be met which are as follows

- The light path travel should be from a lighter medium approaching to a more dense medium

- Angle of incidence should be greater than the critical angle.

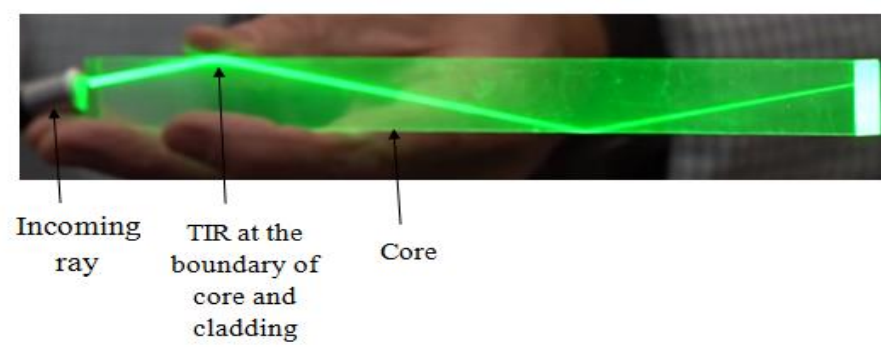

Fig 11. Total internal reflection through optical fiber cable
As mentioned earlier the whole solar concentrator assembly is specifically intended to follow the design parameters of cassegrain reflector that is used in modern days reflecting telescopes. This type of reflectors use a combination of two concave mirrors out of which one acts as a primary reflector and the other as secondary reflector. The rays coming directly from the sun strikes the primary reflector which guides the incident rays on to the secondary reflector and thus hitting the target or the focus placed at the center. The solar concentrator was made up of two square plywood plates separated by vertical G.I pipe rods. The two square plywood plates would act as a supporting frame for the primary reflector and secondary reflector. The outer dimensions of the primary square plywood plates were fixed at $700 \mathrm{~mm} \times 700 \mathrm{~mm}$. The secondary reflector frame of the solar collector was made from the square plywood plate cut out from the primary reflector frame, this was basically done to reduce the cost of the reflector frames. The secondary reflector frame outer dimension was fixed at $400 \mathrm{~mm} \times 400$ $\mathrm{mm}$ square plate and a square section of $200 \mathrm{~mm} \times 200 \mathrm{~mm}$ was carved out from this reflector plate. Both the reflector plates that were obtained from a square plywood plate of 700 $\mathrm{mm} \times 700 \mathrm{~mm}$ is shown in Fig. 12.

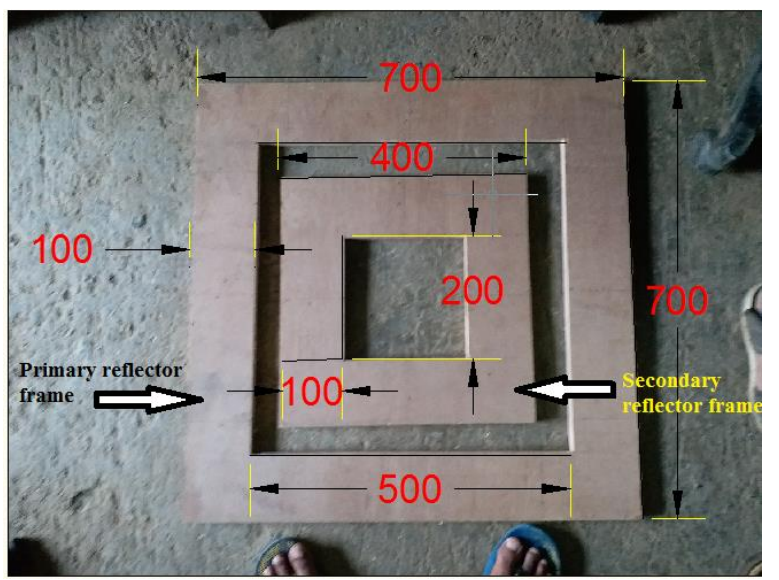

Fig 12. Primary and Secondary reflector frame dimensions

The G.I rods were circular in cross section having a length of $366 \mathrm{~mm}$ and diameter of $19.05 \mathrm{~mm}$ with an effective thickness of $2.48 \mathrm{~mm}$. The length of each G.I rectangular plates attached to the ends of the rods were of $70 \mathrm{~mm} \times 25.40$ $\mathrm{mm} \times 3 \mathrm{~mm}$ with a hole of radius $2.50 \mathrm{~mm}$ drilled on each of them as shown in the Fig. 13.

\subsection{DESIGN OF NON IMAGING CONCENTRATOR}




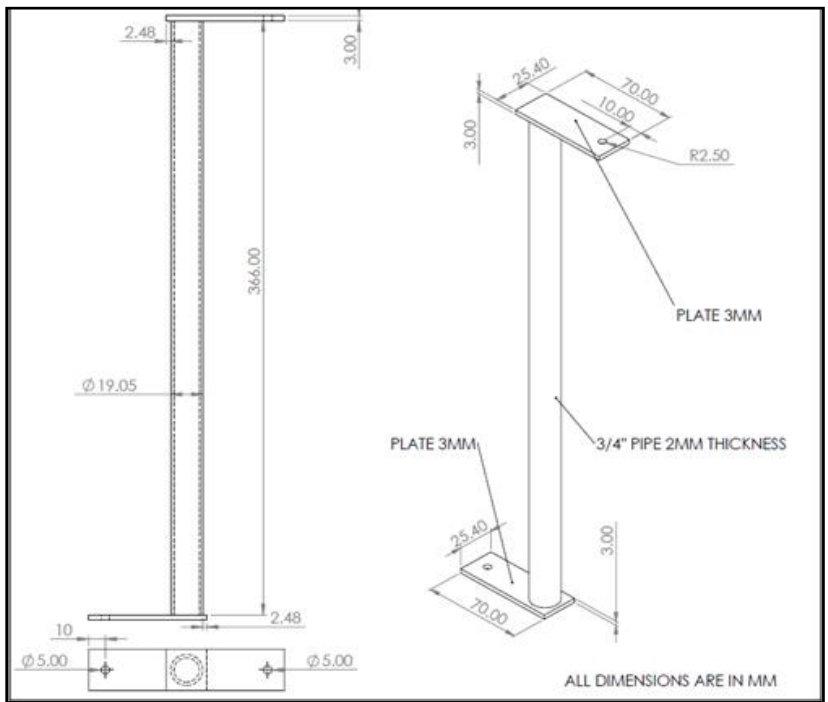

Fig 13. Front, Top and Auxiliary view of support rods prepared in SolidWorks.

The primary reflectors were made up of four reflecting mirrors and each of their dimensions was $400 \mathrm{~mm} \times 100 \mathrm{~mm}$ $\mathrm{x} 6 \mathrm{~mm}$. Four holes were drilled at either side of the primary mirror of diameter $5 \mathrm{~mm}$. These holes were drilled at a distance of $10 \mathrm{~mm}$ and $30 \mathrm{~mm}$ from the horizontal edge side and at $6 \mathrm{~mm}$ from the vertical edge of the mirror. These holes were drilled to attach the primary mirrors to the wedges placed at the bottom with the help of screws. The four mirrors were placed at each side of the square plate at an inclination angle of $15^{\circ}$ in order to reflect the oncoming rays to the secondary reflector. This inclination of $15^{\circ}$ was provided by placing a triangular acrylic wedge which served as a bond plane where the primary frame and the primary reflector could be connected with the help of screws and also provided the necessary inclination required for the primary reflecting mirrors. The detailed dimensions of the wedge and primary mirrors is shown in Fig. 14 and Fig. 15. Secondary reflector was prepared by attaching the secondary mirror with the secondary square plywood plates with the help of screws to form a tight bonding between them. Hence in order to fix the mirrors on to the plates a total of 8 holes of diameter $5 \mathrm{~mm}$ were drilled into the mirrors. The placement of the holes were at drilled on their respective eight corners formed at the outer edge and the inner edge. The centre of the holes was in diagonal fashion from the edges with a distance of 10 $\mathrm{mm}$ apart from the edges. A diagrammatic representation of the secondary mirror and its hole placements are shown in Fig. 16.

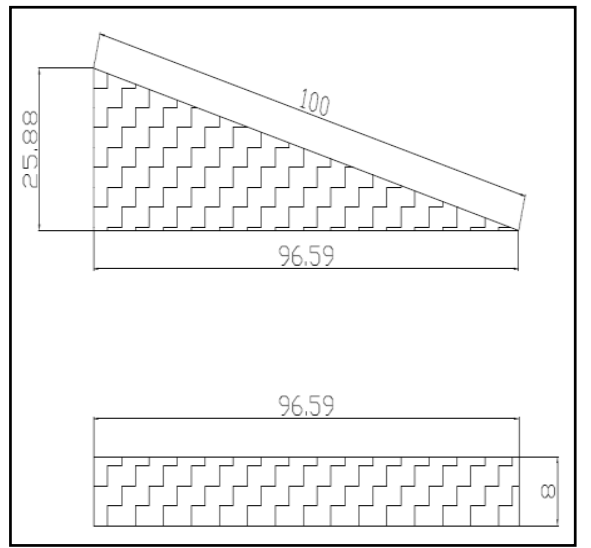

Fig 14. Front and top view of wedge

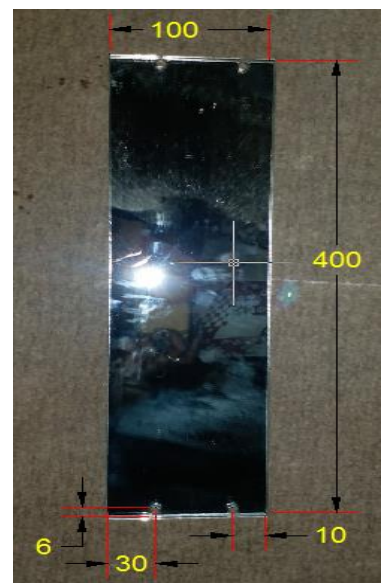

Fig 15. Primary mirror dimensions

\subsection{DESIGN OF LIGHTGUIDNG SYSTEM}

The solar concentrator was erected by attaching the primary reflector frame, primary mirror, wedge in between them and tightening them with screws which formed the primary reflector. Similarly the secondary reflector plate and the secondary mirrors were screwed together in the same fashion.

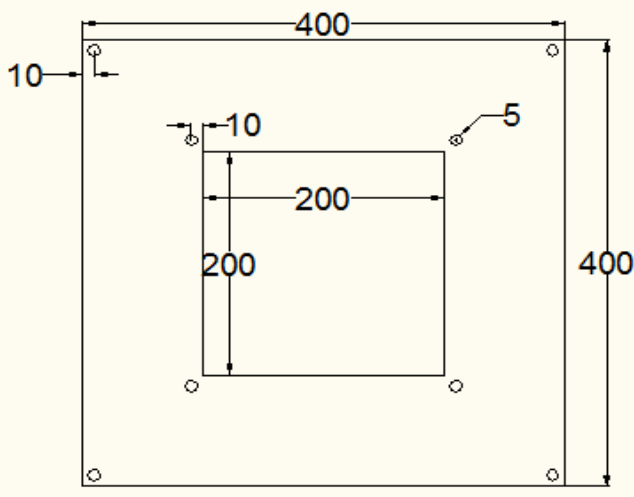

Fig 16. Secondary mirror dimensions

After the reflectors were prepared the supporting rods were added at each of the four inner corners of the primary frame, such that the upper G.I flat plates holes matched with the holes on the outer edges of the secondary frame. Fig. 17. shows the assembly of the solar connector parts.

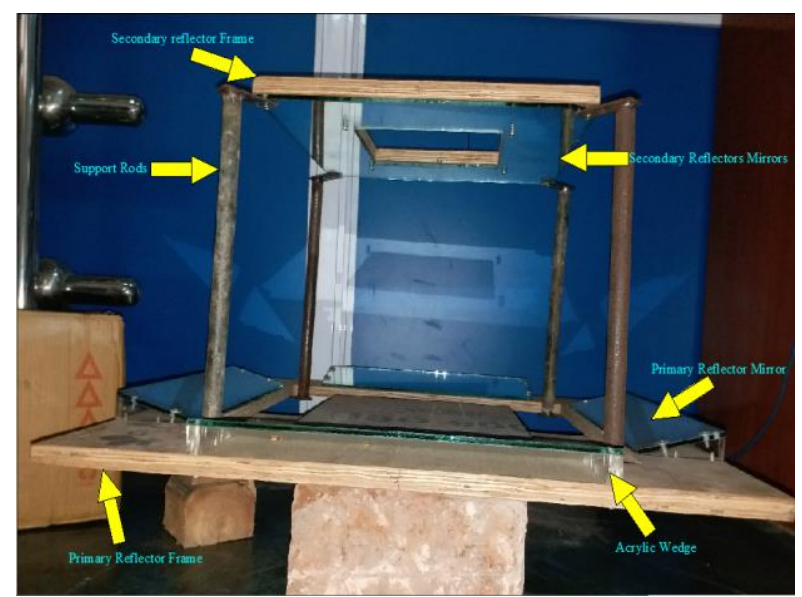

Fig 17. Solar collector assembly with parts.

The light guiding system consists of two components i.e optical fibers and target plate. The target plate is the area 
where the incident rays are focused from the reflectors. These concentrated rays are then received at one end of the optical fiber and then it is transported through its interiors due to total internal reflection phenomena. In order to design the light guiding system and its components a ray tracing was performed in AutoCAD software in order to determine the dimension of the focus plate and the spacing of the holes on the focus plate. A 2-D design of the solar collector with the focus plate was constructed in AutoCAD that as shown in Fig. 18 it represents the noon condition of the day at which the sun would be directly above the solar concentrator. The rays from the sun directly falls onto the primary reflector mirror which is placed at an angle of $15^{\circ}$ to the horizontal from where it gets reflected to secondary mirror from and hits the target plane or the focus plane after reflection.

The ray tracing of the rays reflected from the center of the primary reflector to the target plane yielded an angle of $23^{\circ}$ which was in the half acceptance angle of the optical fiber. Hence the design was deemed to be appropriate and fit for the placement of optical fiber along that length of the plane. In order to make up for the constant change of the sun motion in the sky the length adopted for the target plane was $300 \mathrm{~mm}$ x $300 \mathrm{~mm}$.

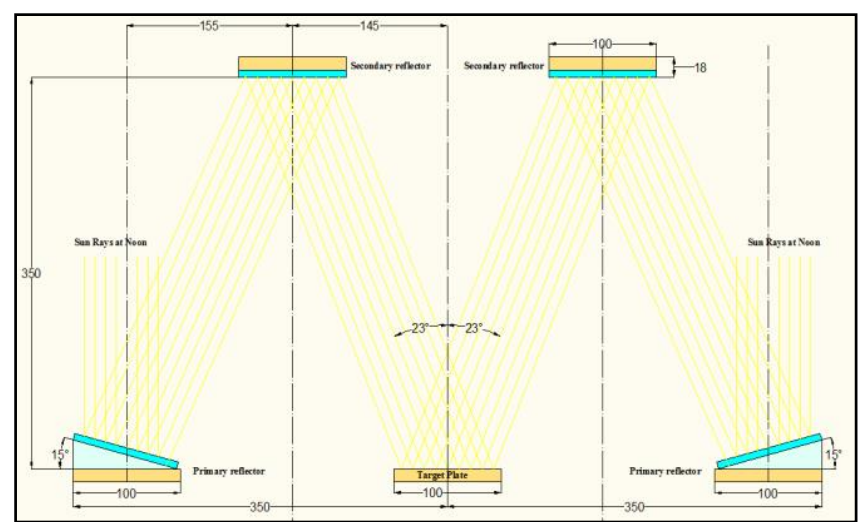

Fig 18. 2-D ray tracing in AutoCAD at noon

A square plate section of $300 \mathrm{~mm}$ x $300 \mathrm{~mm}$ was cut from the marine plywood to form the target plane. This plate was divide into 9 rows and 9 columns with a center to center spacing of $30 \mathrm{~mm}$ in order to cover the whole area of the target plane which is shown in Fig. 19. At each of the meeting points of the rows and column a hole of $3 \mathrm{~mm}$ was drilled for the placement of fiber optical wires. A total of 81 meeting points were obtained, in a concentric square pattern, two fiber optical fiber wires were placed in each of the holes on the outer edge of the square pattern and all the other holes were packed with three fiber optical wires. The fiber wires were glued in the holes with the help of glue gun in order to bond the wires in the hole and to resist any slippage of the fiber wires from the holes which is shown in Fig. 20.

This target plane was attached to the solar collector with the help of six rectangular plywood plates of $170 \mathrm{~mm}$ x $40 \mathrm{~mm}$. These plates ends were screwed to the target plane and the primary reflector frame to keep both of the planes in same level and to support the target plane which is shown in Fig. 21.

To verify that the rays reflected from the reflectors would hit the target plane well inside the half acceptance angle of the optical fibers, an experimental setup was prepared and tested. This experimental setup consisted of two silver coated mirrors which depicted the primary and secondary reflector mirrors, a plywood piece and a laser. The setup of the assembly including the dimensions is shown in Fig. 22. The dimensions of the two mirrors were $100 \mathrm{~mm} \times 100 \mathrm{~mm}$ as this is 2-D view hence only one side of the dimension would be visible.

The two mirrors were separated from each other with a vertical distance of $350 \mathrm{~mm}$ and by $155 \mathrm{~mm}$ center to center horizontal distance from each other. The secondary mirror was placed at a center to center distance of $145 \mathrm{~mm}$ from the optical fiber cable, but in this assembly it was replaced by a plywood plate of certain length and width. In order to depict the fiber optical cable a line was etched on plywood plate which acted as a center line of the fiber cable and the laser lights were intended to hit at this line after reflection from the mirrors.

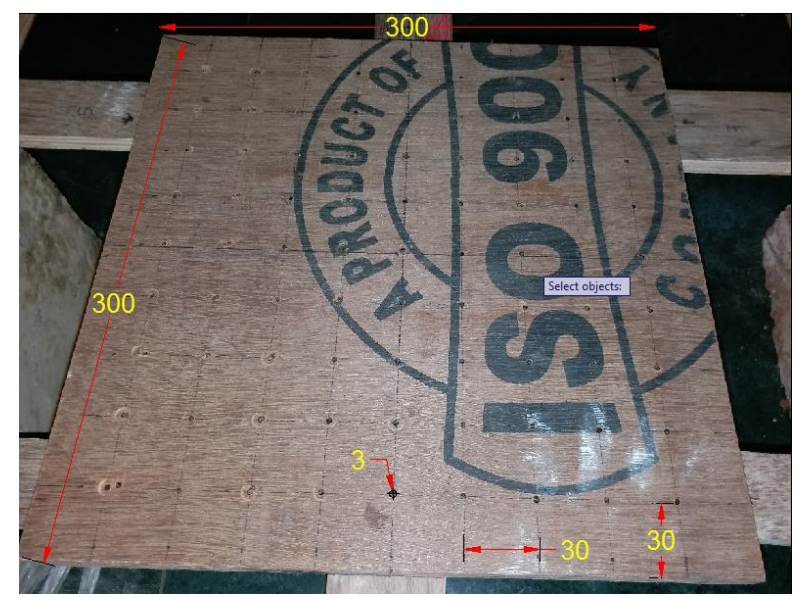

Fig 19. Target plane dimension

This whole procedure was carried out by marking the dimensions on the ground, placing the mirrors at their respective positions and the target plywood with marked center line. After the placement of the parts at their respective positions, a laser light was centered along the enter line of the primary mirror at some distance and the laser light was switched on.

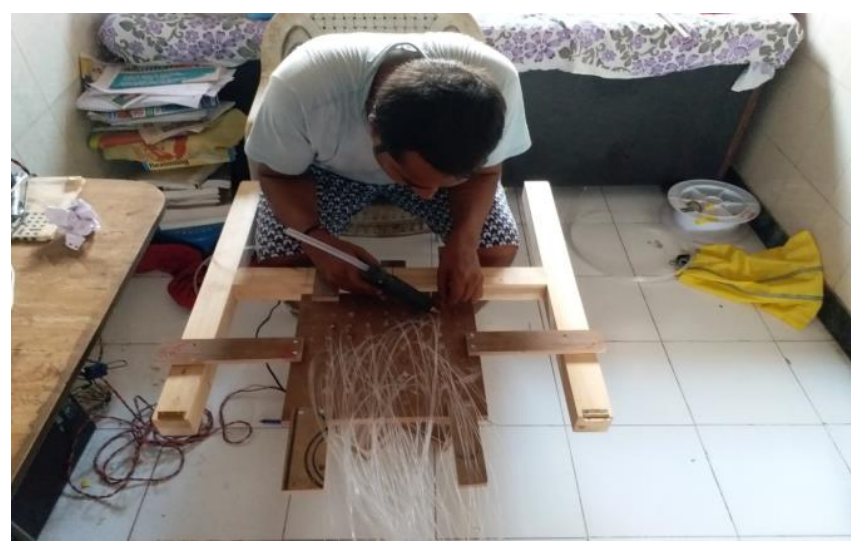

Fig 20. Gluing of optical fibers in holes with help of glue gun 


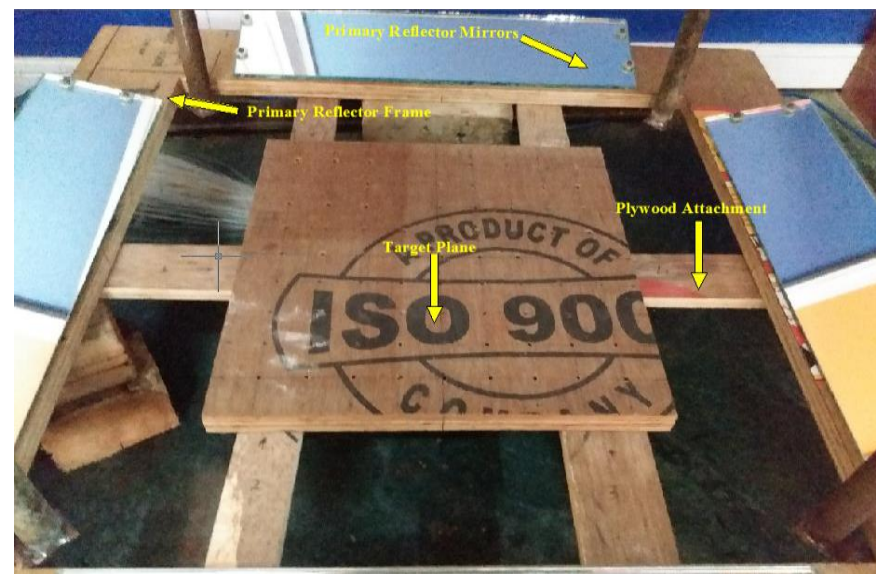

Fig 21. Target plane attachment with primary reflector frame.

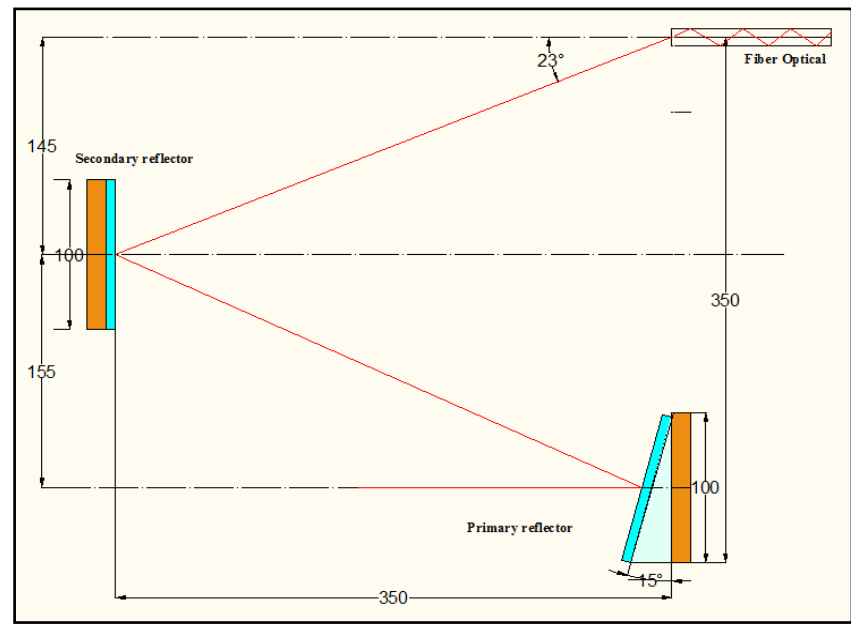

Fig 22. Experimental assembly of ray path verification.

The light directed on the primary mirror got reflected onto the secondary mirror and striked the target plywood at the intended location line. In order to measure the angle at which the light striked the target plywood a protractor was placed in front of the target plane to trace the angle which came around $23^{\circ}$. The angle obtained from 2-D ray tracing in AutoCAD and experimental verification yielded the same results and were in tandem. Hence it proved that the design and dimensions adopted for the solar collector design and the target plane were good for building the prototype under working condition. Fig. 23 shows the experimental setup conducted with the help of lasers for verification.

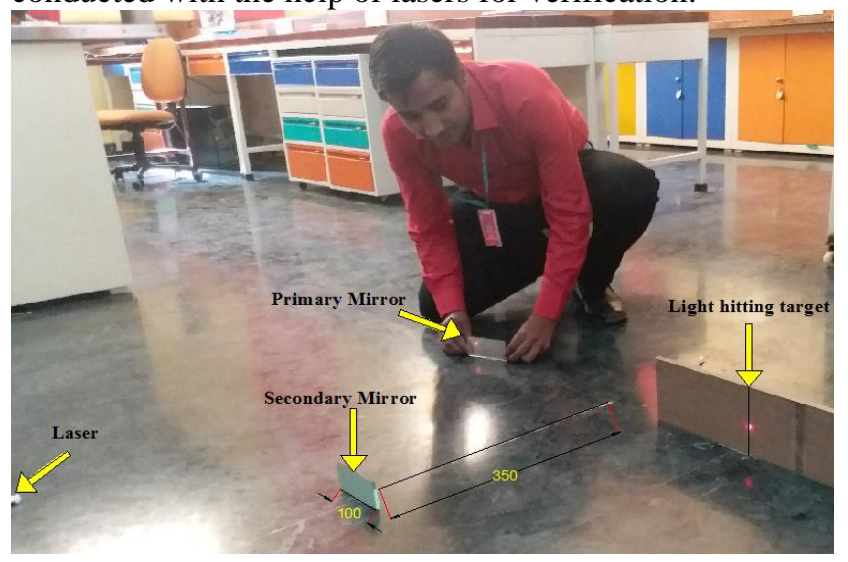

Fig 23. Determination of ray path with laser

\section{TESTING}

A working model of the daylighting system was prepared based on the design inputs and dimensions obtained from the previous stages of design. The day lighting system was placed at its respective location of testing, resting on four concrete cubes placed at each corner. The fiber optical cables from each rows were collected together to form a bundle and the they were wrapped with the help of tape. All these bundles were brought in together to form a circular bundle of $19.05 \mathrm{~mm}$ or 3/4" of an inch, then this circular bundle was inserted into a $19.05 \mathrm{~mm}$ diameter and $2 \mathrm{~mm}$ thick PVC circular pipe. This was done to keep the optical fiber bundles tightly packed inside the pipe and to avoid any slippage of the bundles and shown in Fig. 24.

This PVC pipe containing the optical fiber bundles was inserted into a cardboard box so as to perform the luminous intensity test in a dark room or environment, hence a cardboard box of $17 \times 11 \times 10$ inch was selected. A rectangular slot of $6 \times 4$ inch was driven into the cardboard box so that lux meter and temperature gun could be inserted into it to take the readings of the luminous intensity and the temperature at the end of optical fiber. The whole assembly of the setup is shown in Fig. 25.

A sheet was also prepared with the help of excel to note down the readings of the luminous intensity and temperature test performed on the daylighting system which is shown in Fig. 26.

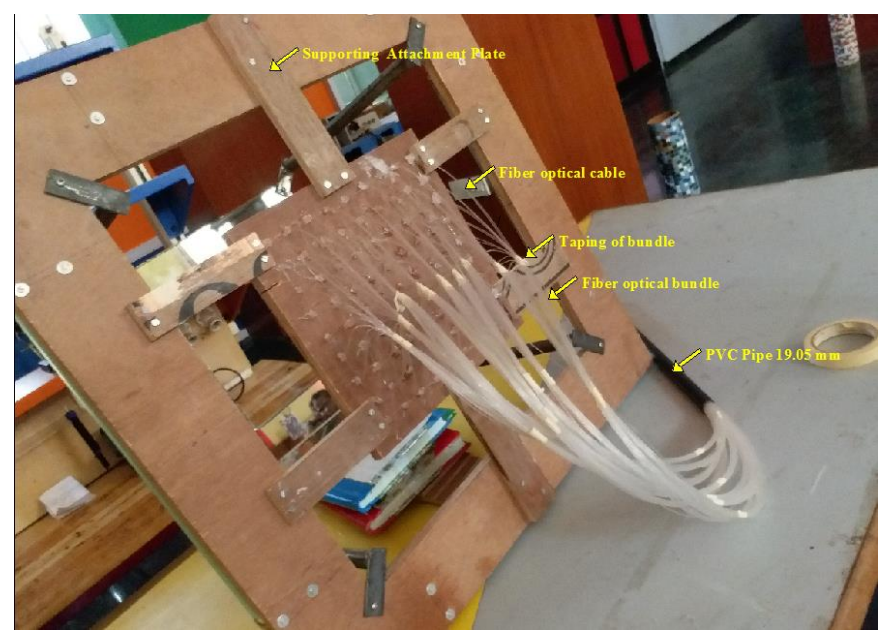

Fig 24. Arrangement of fiber optical bundles into PVC pipe

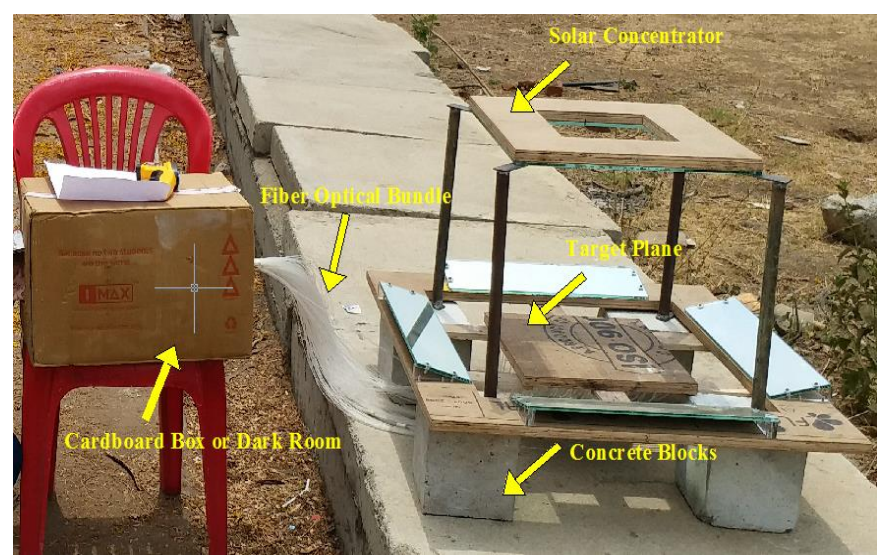

Fig 25. Experimental setup at the location 
This sheet is divided into main two columns of lux intensity and temperature, they are further divided into two columns of output and input end readings. The temperature column is divided into number of columns and the readings are to be taken at three different points on the input end of the target plane to get an average reading at this end. As there can be a possibility of differential temperature on the target plane due to the change in focusing spot of reflectors which is influenced by the suns location in the sky. The time frame of the readings are divided into 15 minutes interval which would span from 10 A.M in the morning to 4 P.M in the afternoon giving 25 readings in a day.

The daylighting system was tested in outdoor conditions in the campus of Pillai HOC campus. The testing was carried out on sunny days of $2 \mathrm{nd}, 3 \mathrm{rd}$, 4th, 6th and 7th June at this location. The normal day temperatures of these 5 days recorded were $35^{\circ} \mathrm{C}, 35^{\circ} \mathrm{C}, 34^{\circ} \mathrm{C}, 35^{\circ} \mathrm{C}, 35^{\circ} \mathrm{C}$ respectively. Before testing the daylighting system a comprehensive study on the sun path followed by the sun over the testing spot was studied and is shown in Fig. 27.

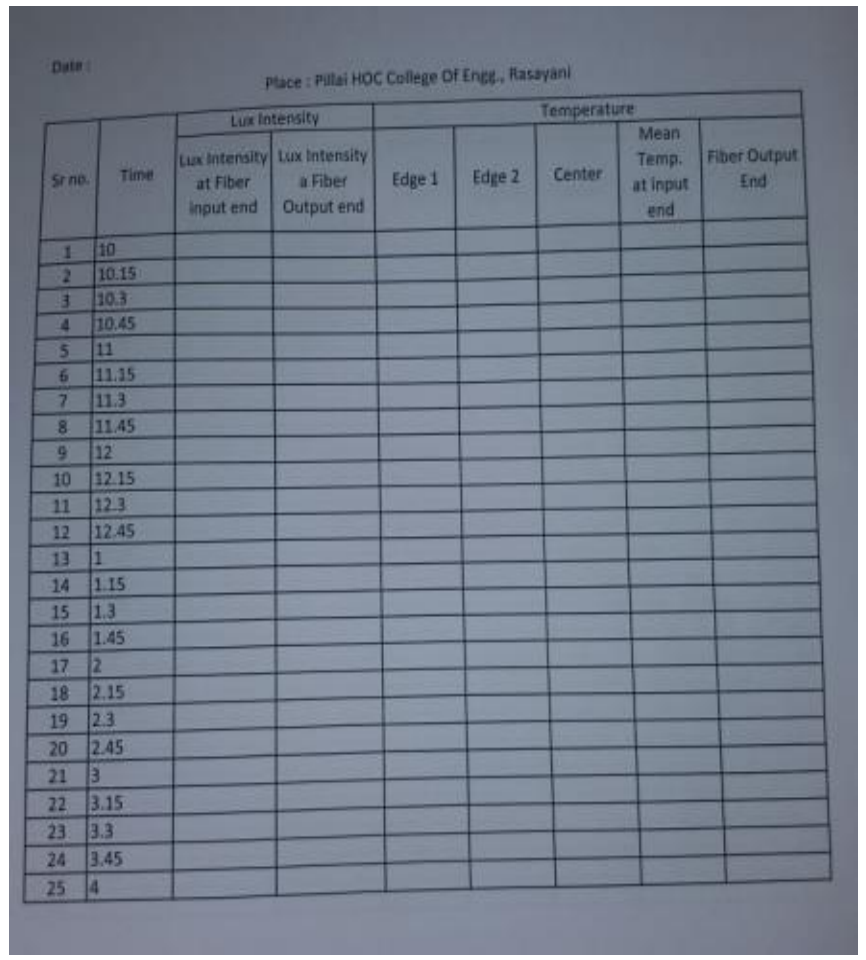

Fig 26. Readings Sheet

For measuring the lux intensity at the output and input ends, a device called as lux meter was used. The lux meter has two components the probe and the displaying meter, the probe consists of sensitive photodiode placed under a white plastic dome structure. The diodes in the probe are very sensitive to light, the plastic dome structure enables a uniform distribution of the light that falls on the diode. The lux meter used for this research work was of Metravi company and the model no. used was 1310 . This model was selected due to its range of measurement which spanned upto 2 lakh lux and the readings obtained were very precise with marginal errors. This model had different modes for measurement and also had an led backlight display panel which would make it easier to note down the readings in complete darkness. Fig.
28 shows the lux meter model and Table 1 gives the specifications of the lux model.

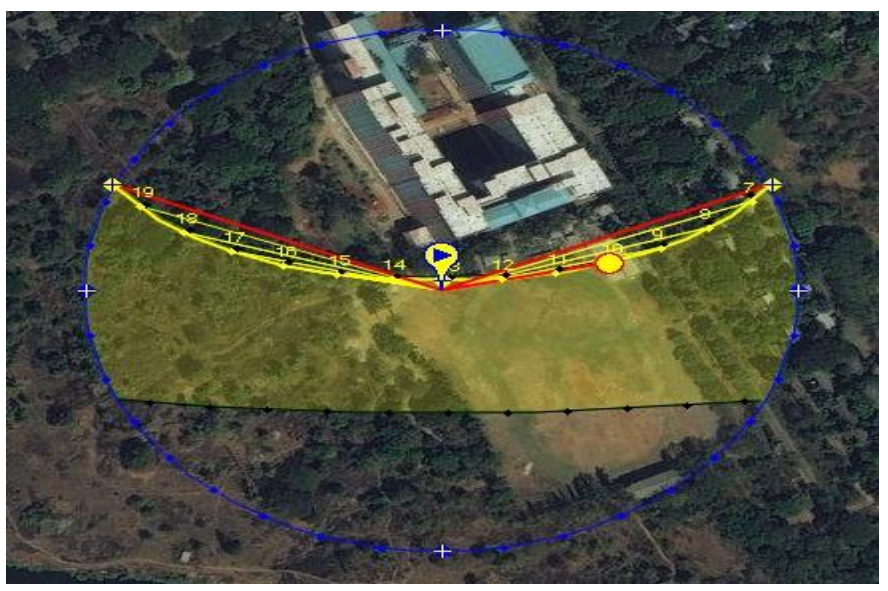

Fig 27 Path followed by the sun over the testing area

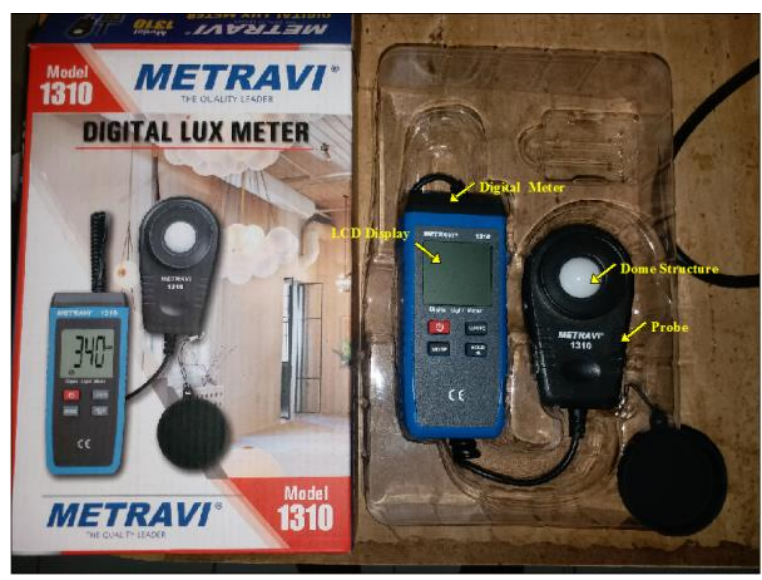

Fig 28. Metravi Lux Meter

Table 1 Specification of Lux Meter

\begin{tabular}{|l|l|}
\hline \multicolumn{2}{|c|}{ Specification of Lux meter ( Metravi 1310) } \\
\hline \multirow{3}{*}{ Display } & $\begin{array}{l}\text { 4 digit LCD screen. Max display } \\
: 9999\end{array}$ \\
\hline Range & $0 \sim 199,900$ Lux \\
\hline \multirow{4}{*}{ Accuracy } & $0 \sim 9999$ Lux - 1 Lux \\
\cline { 2 - 2 } & $\geq 10,000$ Lux - 10 Lux \\
\cline { 2 - 2 } & $\geq 100,000$ Lux - 100 Lux \\
\hline Sampling Rate & $0.5 \mathrm{~s}$ \\
\hline Drop Test & $1 \mathrm{~m}$ \\
\hline Battery & $3^{*} 1.5 \mathrm{~V}(\mathrm{AAA})$ \\
\hline $\begin{array}{l}\text { Operating } \\
\text { environment }\end{array}$ & $0^{\circ} \mathrm{C} \sim 40^{\circ}(\leq 80 \% \mathrm{RH})$ \\
\hline
\end{tabular}

The lux intensity at the input end was measured after a periodic interval of $15 \mathrm{~min}$ over a time period of 10 A.M to 4 P.M every day on respective 5 days of testing as shown in Fig. 29. The readings at the beginning of each time interval was measured and noted down in the input intensity column of the sheet. After the lux intensity at the input end was measured, luminous intensity emitted at the output ends was measured in succession. 


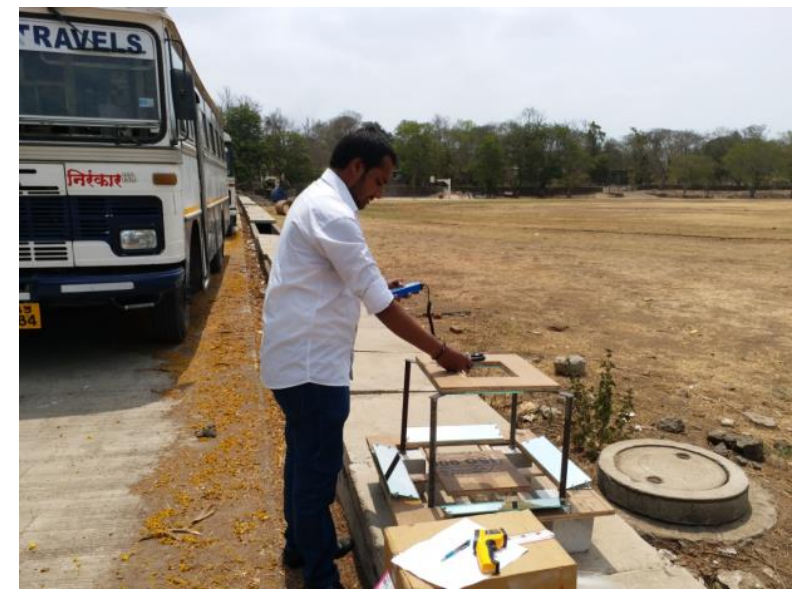

Fig 29. Measuring the lux intensity at the input end

The output lux intensity was taken by inserting the lux meter into the cardboard box which acted as a dark room for measurement of the lux intensity given out by the fiber optical bundles and is shown in Fig. 30 and Fig. 31

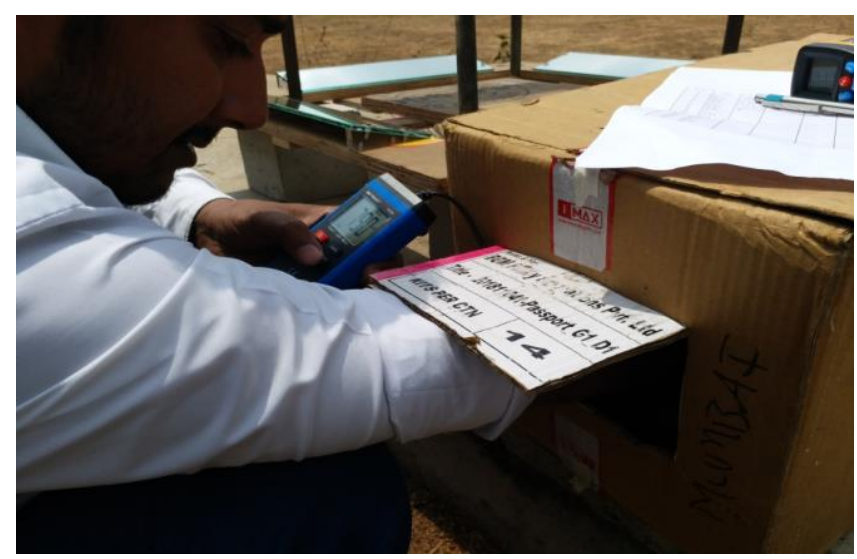

Fig 30. Measuring the lux intensity at the output end of optical fiber bundle

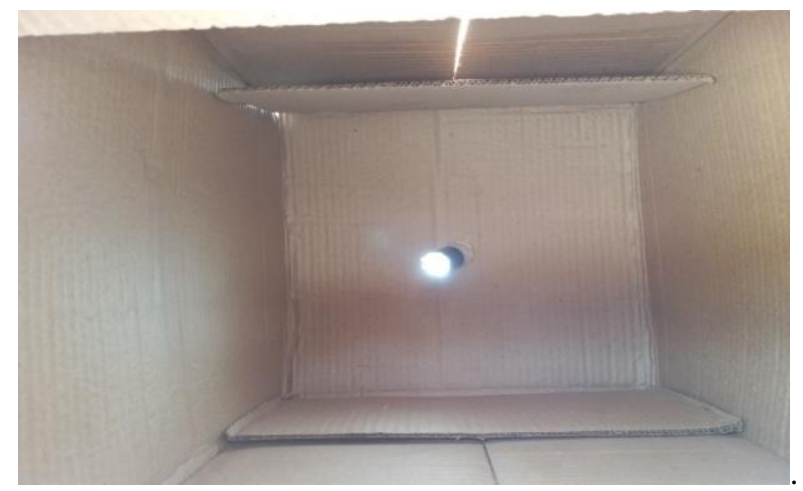

Fig 31. Lux intensity at the output end of optical fiber bundle

As the maximum operating temperature of optical fibers was $70^{\circ} \mathrm{C}$. A IR thermometer which is shown in Fig. 32 was used to constantly measure the temperature at the surface of the target area and at the fiber optical end inside the cardboard box. The IR thermometer ensured easy handling along with quick and precise measurements due to its non contact technology.

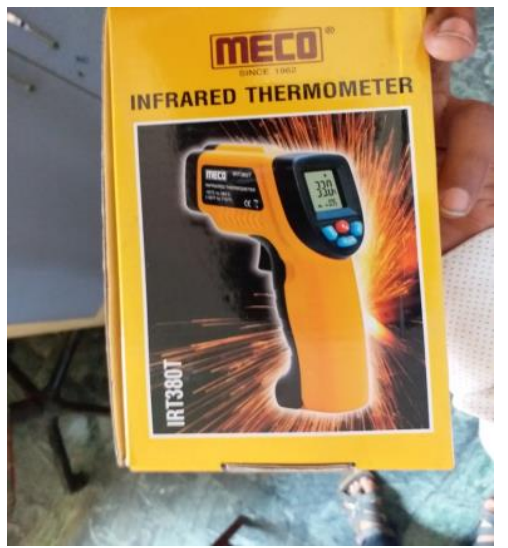

Fig 32. Infrared Thermometer IRT380T

The temperature at the target plane i.e. input end was measured at three points which were at the two edges of the plane and one at the center which is shown in Fig. 33. The temperature readings at the output end of the optical fiber bundle were also taken in order to determine that the temperature was well within the functioning temperature of the optical fiber. The temperature at the output end was measured by keeping the IR thermometer at the opening slot of the cardboard box and directing the laser of the thermometer onto the center of the optical fiber bundle which is shown in Fig. 34.

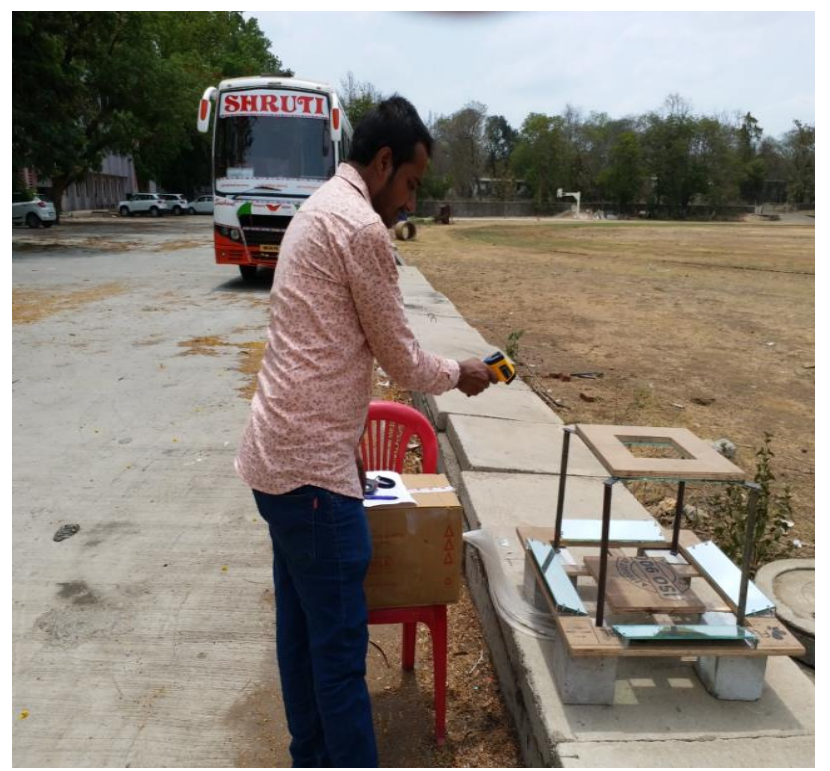

Fig 33. Measurement of temperature at target plane with infrared thermometer

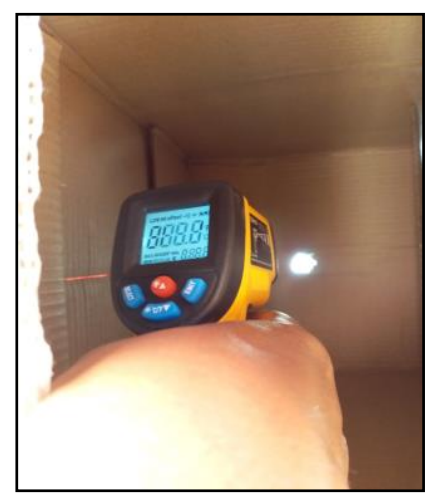


Fig 34. Measurement of temperature at optical fiber end with infrared thermometer

\section{RESULTS}

This chapter presents the results of luminous intensity and temperature studies performed in this research work. An extensive procedure was followed across every stage of this research work to obtain the results. The results of this research work was basically concentrated on knowing the potential luminous intensity which could be derived from the daylighting system at the study area and the temperature fluctuations at the input and output ends.

\subsection{Luminous Intensity}

The luminous intensity was measured by the lux meter at both the input and output ends of the optical fiber. The measurement was taken every day of the testing period which was divided into 25 slots of 15 minutes interval over a time period from morning 10 A.M to 4 P.M in the afternoon. The readings obtained at the input ends were the direct radiation of the sun falling onto the collector at that specific time of measurement.

The values at the input end and output end of the optical fiber was observed directly on the digital screen of the lux meter and noted down in its respective column in the sheet. Similarly, all the other readings were noted down on the sheet at their respective time period in the day. The results so obtained on the respective days are shown in a tabular format in Table 2. A graphical representation in the form of bar and line graph is plotted with Time Vs Lux intensity at output in Fig. 35 and Fig. 36.

From observing the graph it can be understood that the lux intensity gradually increases from 10 A.M to 1.45 P.M and after which it gradually decreases upto 4 P.M. On analyzing the graph it can be observed that the lux intensity increases and decreases gradually and no constant value of lux intensity are observed at any two time frames. The graph attains a steep increase and decrease of lux intensity in between 1 P.M and 2.30 P.M, attaining its peak value at 1.45 P.M. As all the readings achieve its peak value at 1.45 P.M which indicates a solar noon at that spot. A solar noon indicates that the sun is directly above the daylighting system and gives out maximum solar radiation to the system.

From the line graph it can be observed that the lux intensity output between 12.30 P.M to 2.45 P.M yields an average lux intensity output of above 800 lux and the maximum intensity is achieved at 1.45 P.M. At this time interval, it is seen that the lux intensity achieved is maximum for all testing days which are 1321,1420,1489,1389,1296 lux and out of these days the maximum intensity value of 1489 lux was achieved on 4th of June. The intensity from 10 A.M to 12.15 and 2.30 P.M to 4 P.M has an typical value of above 350 lux and the minimum value of lux intensity is obtained as 323 lux on 7 th June at 4 P.M.

\subsection{Temperature at Input and Output End}

The temperature measurements were taken at 3 points on the target plane and at the optical fiber bundle outer end. An IR thermometer of model no.380T was used to measure the temperatures at these points. The temperature measured at 3 points of the target plane was averaged to get the average temperature at the surface of the target plane. The values of temperature output at the fiber optical end was taken at the center of the fiber optical bundle. The readings results so obtained on 2 nd \& 3rd, 4th \& 6th, 7th June are shown in a tabular format in Table 3,4 \& 5 .

Table 2 Lux intensity values at the input and output end of optical fibers

\begin{tabular}{|c|c|c|c|c|c|c|c|c|c|c|c|}
\hline \multicolumn{2}{|r|}{ Date } & \multirow{2}{*}{\multicolumn{2}{|c|}{\begin{tabular}{|c|} 
2nd June \\
Luminous Intensity
\end{tabular}}} & \multirow{2}{*}{\multicolumn{2}{|c|}{\begin{tabular}{|c|} 
3rd June \\
Luminous Intensity
\end{tabular}}} & \multirow{2}{*}{\multicolumn{2}{|c|}{$\begin{array}{c}\text { 4th June } \\
\text { Luminous Intensity }\end{array}$}} & \multirow{2}{*}{\multicolumn{2}{|c|}{$\begin{array}{c}\text { 6th June } \\
\text { Luminous Intensity }\end{array}$}} & \multirow{2}{*}{\multicolumn{2}{|c|}{$\begin{array}{c}\text { 7th June } \\
\text { Luminous Intensity }\end{array}$}} \\
\hline Sr & & & & & & & & & & & \\
\hline no. & Time & Input & Output & \begin{tabular}{|l|} 
Input \\
\end{tabular} & Output & Input & Output & \begin{tabular}{|l|} 
Input \\
\end{tabular} & Output & Input & Output \\
\hline 1 & 10:00:00 AM & 623 & 342 & 650 & 355 & 642 & 348 & 637 & 350 & 652 & 358 \\
\hline 2 & 10:15:00 AM & 689 & 375 & 701 & 384 & 679 & 364 & 668 & 360 & 697 & 381 \\
\hline 3 & 10:30:00 AM & 712 & 400 & 735 & 436 & 722 & 425 & 746 & 449 & 728 & 429 \\
\hline 4 & 10:45:00 AM & 761 & 447 & 784 & 482 & 759 & 436 & 776 & 477 & 792 & 493 \\
\hline 5 & 11:00:00 AM & 795 & 486 & 815 & 509 & 825 & 515 & 793 & 496 & 802 & 498 \\
\hline \begin{tabular}{l|l}
6 \\
\end{tabular} & $11: 15: 00 \mathrm{AM}$ & 817 & 511 & 840 & 53 & 859 & 552 & 813 & 503 & 822 & 513 \\
\hline 7 & $11: 30: 00 \mathrm{AM}$ & 832 & 29 & 867 & 571 & 876 & 632 & 827 & 535 & 835 & 532 \\
\hline 8 & 11:45:00 AM & 865 & 568 & 881 & 647 & 898 & 734 & 859 & 561 & 856 & 549 \\
\hline 9 & 12:00:00 PM & 889 & 652 & 906 & 762 & 918 & 760 & 882 & 649 & 883 & 645 \\
\hline 10 & $12: 15: 00 \mathrm{PM}$ & 902 & 756 & 925 & 832 & 935 & 856 & 912 & 802 & 909 & 760 \\
\hline 11 & $12: 30: 00 \mathrm{PM}$ & 918 & 808 & 948 & 869 & 968 & 886 & 937 & 859 & 924 & 831 \\
\hline 12 & $12: 45: 00 \mathrm{PM}$ & 947 & 865 & 989 & 925 & 991 & 932 & 975 & 893 & 958 & 909 \\
\hline 13 & 1:00:00 PM & 984 & 916 & 1086 & 1098 & 1100 & 1203 & 1003 & 1056 & 993 & 939 \\
\hline 14 & 1:15:00 PM & 1096 & 1115 & 1205 & 1298 & 1237 & 1302 & 1198 & 1210 & 1183 & 1187 \\
\hline 15 & 1:30:00 PM & 1195 & 1207 & 1256 & 1319 & 1284 & 1383 & 1234 & 1256 & 1210 & 1273 \\
\hline 16 & 1:45:00 PM & 1259 & 1321 & 1315 & 1420 & 1392 & 1489 & 1301 & 1389 & 1283 & 1296 \\
\hline 17 & 2:00:00 PM & 1120 & 1210 & 1246 & 1313 & 1273 & 1376 & 1256 & 1298 & 1137 & 1224 \\
\hline 18 & 2:15:00 PM & 1014 & 1086 & 1157 & 1186 & 1176 & 1203 & 1034 & 1093 & 1089 & 934 \\
\hline 19 & 2:30:00 PM & 934 & 854 & 1046 & 1054 & 1081 & 1129 & 958 & 873 & 943 & 859 \\
\hline 20 & 2:45:00 PM & 881 & 647 & 953 & 916 & 937 & 862 & 912 & 802 & 899 & 735 \\
\hline 21 & 3:00:00 PM & 837 & 556 & 869 & 568 & 861 & 559 & 842 & 535 & 839 & 532 \\
\hline 22 & 3:15:00 PM & 810 & 499 & 826 & 520 & 813 & 503 & 817 & 511 & 812 & 504 \\
\hline 23 & 3:30:00 PM & 768 & 483 & 781 & 479 & 773 & 489 & 765 & 479 & 760 & 447 \\
\hline 24 & 3:45:00 PM & 702 & 386 & 729 & 430 & 715 & 428 & 721 & 425 & 706 & 391 \\
\hline 25 & 4:00:00 PM & 589 & 338 & 632 & 357 & 610 & 335 & 595 & 327 & 591 & 323 \\
\hline
\end{tabular}

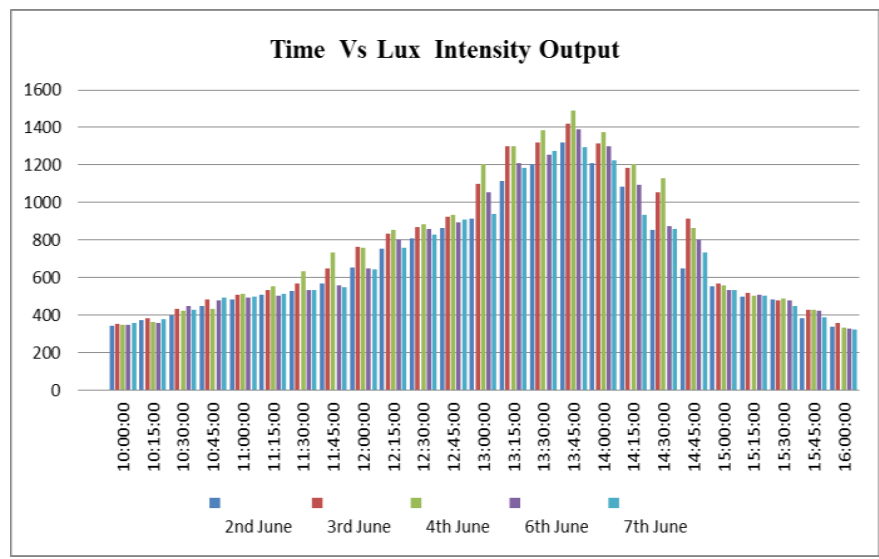

Fig 35. Graphical representation of the lux intensity at output end obtained over 5 days.

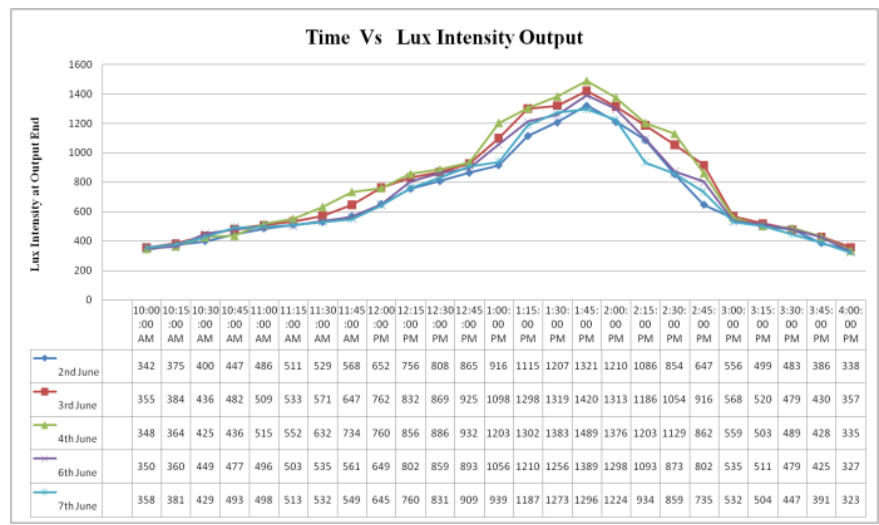

Fig 36. Graphical representation of the lux intensity at output end on a line chart

In Fig. 37 and Fig. 38 a graphical representation in the form of bar chart is provided for Time Vs Mean Temperature at target plane and Time Vs Temperature at output end of fiber. The temperatures are assigned and represented in various colour for different days. It can be observed that in Fig. 37 i.e. Time Vs Mean Temperature at target plane, the graph 
rises slowly from 10 A.M to 11.15 A.M which indicates rise in temperature as the hour progresses.

Table 3 Temperature values on 2 nd \& 3rd June at the input and output end of fiber

\begin{tabular}{|c|c|c|c|c|c|c|c|c|c|c|c|}
\hline \multicolumn{2}{|r|}{ Date } & \multirow{2}{*}{\multicolumn{5}{|c|}{$\begin{array}{c}\text { 2nd June } \\
\text { Temperature } \\
\end{array}$}} & \multirow{2}{*}{\multicolumn{5}{|c|}{$\begin{array}{c}\text { 3rd June } \\
\text { Temperature }\end{array}$}} \\
\hline \multirow[b]{2}{*}{$\begin{array}{c}\text { Sr } \\
\text { no. }\end{array}$} & \multirow[b]{2}{*}{ Time } & & & & & & & & & & \\
\hline & & Edge 1 & Edge 2 & Center & \begin{tabular}{|c|} 
Mean \\
Temp \\
at input
\end{tabular} & \begin{tabular}{|c} 
Fiber \\
output \\
end
\end{tabular} & Edge 1 & Edge 2 & Center & \begin{tabular}{|c|} 
Mean \\
Temp \\
at input
\end{tabular} & $\begin{array}{r}\text { Fiber } \\
\text { outpu } \\
\text { end }\end{array}$ \\
\hline 1 & \begin{tabular}{|l|}
$10: 00: 00 \mathrm{AM}$ \\
\end{tabular} & 36.4 & 33.9 & 35.5 & 35.3 & 33.2 & 37.2 & 35.4 & 36.3 & 36.3 & 34.1 \\
\hline 2 & 10:15:00 AM & 38.1 & 36.9 & 33.9 & 36.3 & 35.7 & 38.1 & 38.5 & 37.6 & 38.1 & 34.6 \\
\hline 3 & \begin{tabular}{|l|}
$10: 30: 00 \mathrm{AM}$ \\
\end{tabular} & 39.3 & 37.3 & 3 & 38.2 & 36.2 & 38.7 & 39.1 & 38.2 & 38.7 & 35.2 \\
\hline 4 & \begin{tabular}{|l|}
$10: 45: 00 \mathrm{AM}$ \\
\end{tabular} & 40.7 & 38.9 & 37.2 & 38.9 & 37.3 & 42.7 & 42.9 & 41.3 & 42.3 & 36.1 \\
\hline 5 & 11:00:00 AM & 42.6 & 40.9 & 38.8 & 40.8 & 37.6 & 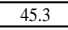 & 42.9 & 42.4 & 43.5 & 36.8 \\
\hline 6 & 11:15:00 AM & 43.6 & 42.4 & 3 & 41.6 & 38.4 & 4 & 43.2 & 44.9 & 43.8 & 38.2 \\
\hline 7 & 11:30:00 AM & 51.9 & 45 & 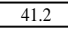 & 46.1 & 39.2 & 45.1 & 43.2 & 42.1 & 43.5 & 38.9 \\
\hline 8 & \begin{tabular}{|l|}
$11: 45: 00 \mathrm{AM}$ \\
\end{tabular} & 46.4 & 4 & 4 & 46.5 & 40.3 & 52.1 & 51.7 & 50.3 & 51.4 & 42.3 \\
\hline 9 & \begin{tabular}{|l|}
$12: 00: 00 \mathrm{PM}$ \\
\end{tabular} & 42.3 & 43.7 & 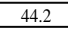 & 43.4 & 40.8 & 47.3 & 48.9 & 49.1 & 48.4 & 41.7 \\
\hline 10 & \begin{tabular}{|l|}
$12: 15: 00 \mathrm{PM}$ \\
\end{tabular} & 41.8 & 40.5 & 41.3 & 41.2 & 39.3 & 45.1 & 46.9 & 48.3 & 46.8 & 41.2 \\
\hline 11 & \begin{tabular}{|l|}
$12: 30: 00 \mathrm{PM}$ \\
\end{tabular} & 39.1 & 38.3 & 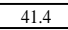 & 39.6 & 38.2 & 50.1 & 48.7 & 49.2 & 49.3 & 43.4 \\
\hline 12 & \begin{tabular}{|l|}
$12: 45: 00 \mathrm{PM}$ \\
\end{tabular} & 42.7 & 43.9 & 41.9 & 42.8 & 38.7 & 54.7 & 55.1 & 56.8 & 55.5 & 44.7 \\
\hline 13 & \begin{tabular}{|l|}
$1: 00: 00 ~ P M$ \\
\end{tabular} & 49.8 & 52.3 & 489 & 50.3 & 42.3 & 58.2 & 60.8 & 60.2 & 59.7 & 48.2 \\
\hline 14 & \begin{tabular}{|l|}
$1: 15: 00 \mathrm{PM}$ \\
\end{tabular} & 53.2 & 47.9 & 55 & 52.0 & 43.9 & 49.2 & 52.3 & 54.1 & 51.9 & 46.4 \\
\hline 15 & \begin{tabular}{|l|}
$1: 30: 00 \mathrm{PM}$ \\
\end{tabular} & 48.2 & 46.8 & 58 & 51.0 & 44.2 & 54.3 & 57.2 & 56. & 56.0 & 50.1 \\
\hline 16 & \begin{tabular}{|l|}
$1: 45: 00 \mathrm{PM}$ \\
\end{tabular} & 47.3 & $4=1$ & $T$ & 45.3 & 39.6 & 51.2 & 50.4 & 52.3 & 51.3 & 47.3 \\
\hline 17 & \begin{tabular}{|l|} 
2:00:00 PM \\
\end{tabular} & 45.7 & 41.3 & 42.8 & 43.3 & 40.3 & 43.1 & 44.2 & 42.6 & 43.3 & 41.9 \\
\hline 18 & \begin{tabular}{|l|}
$2: 15: 00 \mathrm{PM}$ \\
\end{tabular} & 46 & & & & 38.5 & & & 41. & 42.6 & 39.2 \\
\hline 19 & \begin{tabular}{|l|}
$2: 30: 00 \mathrm{PM}$ \\
\end{tabular} & 47.9 & 46.3 & 41.3 & 45.2 & 39.8 & 41.7 & 42.9 & 43.3 & 42.6 & 38.7 \\
\hline 20 & \begin{tabular}{|l|}
$2: 45: 00 \mathrm{PM}$ \\
\end{tabular} & 45. & 47 & 44.8 & 45.8 & 40.4 & 4 & 45.3 & 44.4 & 44.0 & 39.8 \\
\hline 21 & \begin{tabular}{|l|}
$3: 00: 00 \mathrm{PM}$ \\
\end{tabular} & 44.6 & 46.5 & 45.2 & 45.4 & 41.3 & 42.3 & 47.3 & 44.1 & 44.6 & 40.6 \\
\hline 22 & \begin{tabular}{|l|}
$3: 15: 00 \mathrm{PM}$ \\
\end{tabular} & 43.4 & 45.4 & 45.2 & 44.7 & 40.8 & 42.1 & 46.4 & 43.2 & 43.9 & 40.3 \\
\hline 23 & \begin{tabular}{|l|}
$3: 30: 00 \mathrm{PM}$ \\
\end{tabular} & 42.1 & 44.9 & 43 & 43.3 & 39.9 & 41.9 & 44.5 & 43.5 & 43.3 & 39.3 \\
\hline 24 & \begin{tabular}{|l|}
$3: 45: 00 \mathrm{PM}$ \\
\end{tabular} & 41.5 & 43.2 & 42.2 & 42.3 & 37.8 & 41.5 & 42.3 & 42.7 & 42.2 & 38.7 \\
\hline 25 & \begin{tabular}{|l|}
$4: 00: 00 \mathrm{PM}$ \\
\end{tabular} & 40.8 & 42.1 & 41.2 & 41.4 & 37.2 & 40.9 & 42.1 & 42.6 & 41.9 & 37.6 \\
\hline
\end{tabular}

A temperature drop is observed for a little period of time till 12.30 P.M, after which the graph rises gradually till 1 P.M where a maximum peak value of around $60^{\circ} \mathrm{C}$ is observed for 3rd June. The graph then has a steep decrease till 2 P.M and follows a elliptical curve from there onwards. From the graph of Time Vs Temperature at output end of fiber that is shown in Fig. 39 it can be seen that the its rises steadily from 10 A.M to 11.15 A.M and remains constant with gradual increase and decrease over the time period, while achieving its maximum temperature of $50^{\circ} \mathrm{C}$ at 1.30 P.M on $3 \mathrm{rd}$ of June. A graphical representation of line chart is shown in Fig. 38 and Fig. 40 with the temperature values obtained at a given time of the days for all days. On comparing both the graph it can be observed that 3rd June line gives the highest temperature at both ends. Also the graph in Fig 38 and Fig. 40 bear a similarity with each other with a gradual increase and decrease at the start and end of the day, while peaking between the middle hours of the day.

Table 4 Temperature values on 4 th $\& 6$ th June at the input and output end of fiber

\begin{tabular}{|c|c|c|c|c|c|c|c|c|c|c|c|}
\hline \multirow[b]{3}{*}{$\begin{array}{c}\text { Sr } \\
\text { no. }\end{array}$} & Date & \multirow{2}{*}{\multicolumn{5}{|c|}{$\begin{array}{c}\text { 4th June } \\
\text { Temperature }\end{array}$}} & \multirow{2}{*}{\multicolumn{5}{|c|}{$\begin{array}{c}\text { 6th June } \\
\text { Temperature }\end{array}$}} \\
\hline & \multirow[b]{2}{*}{ Time } & & & & & & & & & & \\
\hline & & Edge 1 & Edge 2 & Center & \begin{tabular}{|c|} 
Mean \\
Temp \\
at input \\
\end{tabular} & $\begin{array}{c}\text { Fiber } \\
\text { output } \\
\text { end }\end{array}$ & Edge 1 & Edge 2 & Center & \begin{tabular}{|c|} 
Mean \\
Temp \\
at input
\end{tabular} & $\begin{array}{c}\text { Fiber } \\
\text { output } \\
\text { end }\end{array}$ \\
\hline 1 & 10:00:00 AM & 36.1 & 36.5 & 34.9 & 35.8 & 35.4 & 36 & 35 & 35.4 & 35.5 & 29.3 \\
\hline 2 & 10:15:00 AM & 36.5 & 37.1 & 37.5 & 37.0 & 35.2 & 37 & 37 & 38 & 37.3 & 36.5 \\
\hline 3 & 10:30:00 AM & 38.2 & 39.1 & 38.7 & 38.7 & 34.1 & 38 & 37 & 38 & 37.7 & 37.4 \\
\hline 4 & 10:45:00 AM & 42.1 & 42.7 & 41.3 & 42.0 & 37.5 & 43.4 & 42.4 & 43.7 & 43.2 & 38.9 \\
\hline 5 & 11:00:00 AM & 45.3 & 43.5 & 42.8 & 43.9 & 37.2 & 46.2 & 45 & 44.4 & 45.2 & 41.2 \\
\hline 6 & 11:15:00 AM & 50.9 & 52.2 & 45.4 & 49.5 & 43.9 & 42.6 & 41.7 & 41.6 & 42.0 & 35.6 \\
\hline 7 & 11:30:00 AM & 43.4 & 43.1 & 45.1 & 43.9 & 40.3 & 40.3 & 39.2 & 41.2 & 40.2 & 36.8 \\
\hline 8 & 11:45:00 AM & 42.3 & 43.2 & 44.7 & 43.4 & 40.1 & 41.7 & 41.7 & 44.1 & 42.5 & 35.7 \\
\hline 9 & 12:00:00 PM & 40.8 & 40.7 & 41.5 & 41.0 & 39.7 & 40.9 & 43.9 & 45.8 & 43.5 & 38.3 \\
\hline 10 & 12:15:00 PM & 42.9 & 43.4 & 41.2 & 42.5 & 39.2 & 44.7 & 49.5 & 52.1 & 48.8 & 36.3 \\
\hline 11 & 12:30:00 PM & 41.9 & 41.3 & 42.8 & 42.0 & 39.5 & 46.2 & 49.3 & 60.6 & 52.0 & 38.6 \\
\hline 12 & 12:45:00 PM & 41.2 & 42.8 & 41.8 & 41.9 & 38.9 & 48.3 & 41.6 & 51.7 & 47.2 & 37 \\
\hline 13 & 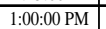 & 40.3 & 41.3 & 42.3 & 41.3 & 38.7 & 49.2 & 45.2 & 53.3 & 49.2 & 38.1 \\
\hline 14 & \begin{tabular}{|l|l}
$1: 15: 00 \mathrm{PM}$ \\
\end{tabular} & 45.1 & 43.6 & 44.2 & 44.3 & 39.9 & 50.3 & 58.8 & 41.4 & 50.2 & 39.2 \\
\hline 15 & \begin{tabular}{|l|}
$1: 30: 00 \mathrm{PM}$ \\
\end{tabular} & 42.1 & 43.2 & 42.6 & 42.6 & 38.2 & 55.9 & 57.8 & 44.1 & 52.6 & 39.5 \\
\hline 16 & \begin{tabular}{|l|}
$1: 45: 00 \mathrm{PM}$ \\
\end{tabular} & 43.9 & 44.6 & 45.1 & 44.5 & 37.9 & 51 & 45.2 & 50.4 & 48.9 & 38.3 \\
\hline 17 & 2:00:00 PM & 51.2 & 52.4 & 50.4 & 51.3 & 45.4 & 42.3 & 44.6 & 42.6 & 43.2 & 39 \\
\hline 18 & \begin{tabular}{|l|}
$2: 15: 00 \mathrm{PM}$ \\
\end{tabular} & 52.3 & 51.6 & 52.7 & 52.2 & 46.3 & 47.9 & 46 & 42.2 & 45.4 & 38.5 \\
\hline 19 & \begin{tabular}{|l|}
$2: 30: 00 \mathrm{PM}$ \\
\end{tabular} & 47.9 & 46.2 & 43.8 & 46.0 & 43.2 & 41.6 & 42.8 & 49.6 & 44.7 & 38.8 \\
\hline 20 & \begin{tabular}{|l|}
$2: 45: 00 \mathrm{PM}$ \\
\end{tabular} & 41.6 & 42.2 & 43.1 & 42.3 & 41.6 & 45.6 & 47 & 44.8 & 45.8 & 38.1 \\
\hline 21 & 3:00:00 PM & 40.9 & 41.7 & 41.2 & 41.3 & 39.7 & 42.3 & 47.3 & 40.2 & 43.3 & 37.1 \\
\hline 22 & \begin{tabular}{|l|}
$3: 15: 00 \mathrm{PM}$ \\
\end{tabular} & 40.2 & 40 & 41 & 40.4 & 38.6 & 44.4 & 47.3 & 44.1 & 45.3 & 38 \\
\hline 23 & \begin{tabular}{|l|l}
$3: 30: 00 \mathrm{PM}$ \\
\end{tabular} & 39.7 & 39.9 & 40.5 & 40.0 & 36.7 & 42 & 45.2 & 43 & 43.4 & 36.9 \\
\hline 24 & \begin{tabular}{|l|l}
$3: 45: 00 \mathrm{PM}$ \\
\end{tabular} & 39.2 & 39.5 & 39.9 & 39.5 & 36.2 & 41.5 & 45 & 46.1 & 44.2 & 37 \\
\hline 25 & \begin{tabular}{|l|}
$4: 00: 00 \mathrm{PM}$ \\
\end{tabular} & 38 & 39.1 & 39.3 & 38.8 & 36.1 & 40.3 & 42.3 & 41.9 & 41.5 & 37.5 \\
\hline
\end{tabular}

This publication is licensed under Creative Commons Attribution CC BY
Table 5 Temperature values on 7th June at the input and output end of fiber

\begin{tabular}{|c|c|c|c|c|c|c|}
\hline \multicolumn{2}{|r|}{ Date } & \multirow{2}{*}{\multicolumn{5}{|c|}{\begin{tabular}{|c|} 
7th June \\
Temperature
\end{tabular}}} \\
\hline \multirow[b]{2}{*}{$\begin{array}{l}\text { Sr } \\
\text { no. }\end{array}$} & \multirow[b]{2}{*}{ Time } & & & & & \\
\hline & & Edge 1 & Edge 2 & Center & $\begin{array}{c}\text { Mean } \\
\text { Temp } \\
\text { at input }\end{array}$ & $\begin{array}{c}\text { Fiber } \\
\text { output } \\
\text { end }\end{array}$ \\
\hline 1 & 10:00:00 AM & 36.2 & 36.9 & 34.1 & 35.7 & 33.5 \\
\hline 2 & $10: 15: 00 \mathrm{AM}$ & 37.1 & 38.5 & 37.9 & 37.8 & 34.9 \\
\hline 3 & 10:30:00 AM & 38.9 & 40.5 & 39.8 & 39.7 & 36.2 \\
\hline 4 & 10:45:00 AM & 42.3 & 42.6 & 41.6 & 42.2 & 37.8 \\
\hline 5 & 11:00:00 AM & 45.5 & 43.6 & 42.4 & 43.8 & 38.7 \\
\hline 6 & 11:15:00 AM & 51.2 & 50.9 & 45.4 & 49.2 & 41.6 \\
\hline 7 & 11:30:00 AM & 43.4 & 43.3 & 45.3 & 44.0 & 39.3 \\
\hline 8 & $11: 45: 00 \mathrm{AM}$ & 42.3 & 43 & 44.5 & 43.3 & 38.2 \\
\hline 9 & 12:00:00 PM & 40.8 & 40 & 41.1 & 40.6 & 37.9 \\
\hline 10 & 12:15:00 PM & 38.1 & 38.3 & 40 & 38.8 & 36.3 \\
\hline 11 & 12:30:00 PM & 42.9 & 43.4 & 41.2 & 42.5 & 39.2 \\
\hline 12 & 12:45:00 PM & 41.9 & 41.3 & 42.8 & 42.0 & 39.2 \\
\hline 13 & 1:00:00 PM & 53 & 47.3 & 58 & 52.8 & 43.4 \\
\hline 14 & 1:15:00 PM & 48.2 & 42.9 & 51 & 47.4 & 40 \\
\hline 15 & 1:30:00 PM & 48.2 & 41.6 & 45.3 & 45.0 & 39.8 \\
\hline 16 & 1:45:00 PM & 47.5 & 45.7 & 43.7 & 45.6 & 40.3 \\
\hline 17 & 2:00:00 PM & 45.6 & 42.1 & 41.6 & 43.1 & 38.8 \\
\hline 18 & $2: 15: 00$ PM & 46 & 44.3 & 42.3 & 44.2 & 41.7 \\
\hline 19 & 2:30:00 PM & 46.8 & 44.7 & 43.7 & 45.1 & 42.3 \\
\hline 20 & $2: 45: 00$ PM & 47 & 52.3 & 51.3 & 50.2 & 45 \\
\hline 21 & 3:00:00 PM & 44.7 & 51.2 & 48.2 & 48.0 & 43.7 \\
\hline 22 & $3: 15: 00$ PM & 42.4 & 47.2 & 50.6 & 46.7 & 42.5 \\
\hline 23 & 3:30:00 PM & 43.4 & 45.4 & 45.2 & 44.7 & 40 \\
\hline 24 & 3:45:00 PM & 41.5 & 42.3 & 43.5 & 42.4 & 39.2 \\
\hline 25 & 4:00:00 PM & 40.9 & 41.5 & 42.1 & 41.5 & 38.1 \\
\hline
\end{tabular}

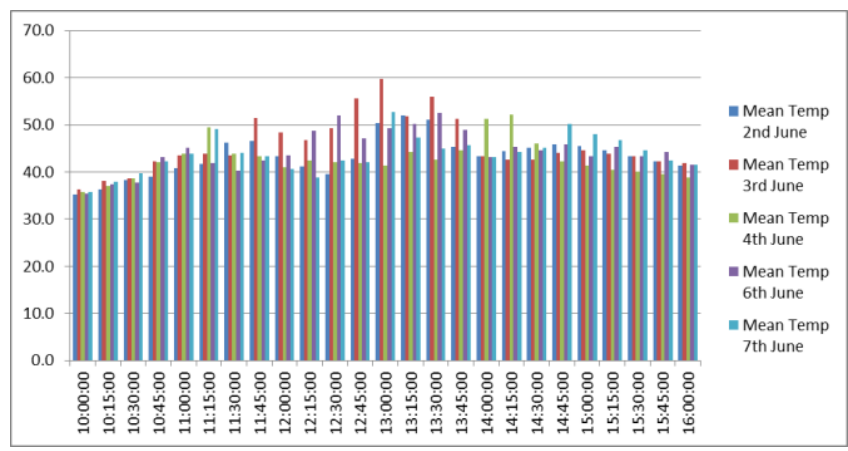

Fig 37 Graphical representation of the Mean Temperature ${ }^{\circ} \mathrm{C}$ obtained over 5 days.

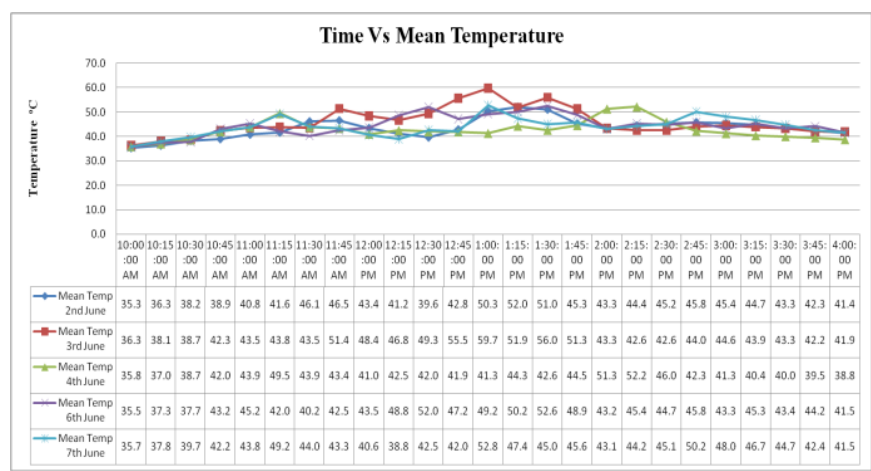

Fig 38 Line Chart representation of Time Vs Mean Temperature ${ }^{\circ} \mathrm{C}$ at target plane 


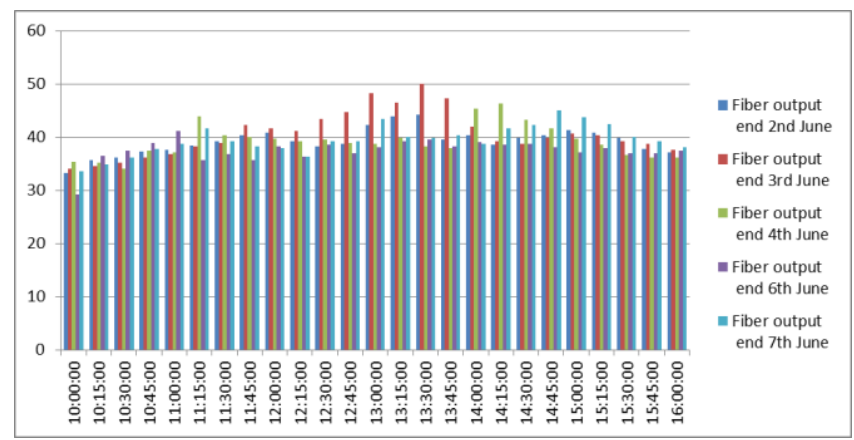

Fig 39. Graphical representation of Temperature ${ }^{\circ} \mathrm{C}$ at Fiber output end obtained over 5 days.

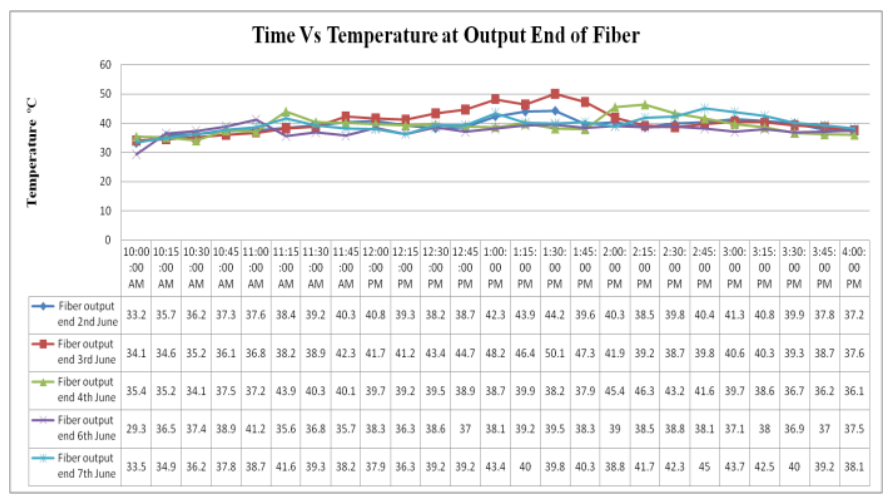

Fig 40. Line Chart representation of Time Vs Temperature at Output End of Fiber.

\section{CONCLUSION}

The luminous intensity recorded at the fiber optical end over the period yielded a minimum value of above 300 lux, while the maximum value were above 1000 lux. Below Table 6 gives an idea about the illumination level or lux required for lighting the interior spaces of different types of building. It can be understood that the lux obtained from the optical fiber daylighting system can easily meet the lighting requirements of these areas in different buildings. The fiber bundle consists of 209 no. of individual fibers which gives a maximum of 1489 lux and minimum 323 lux output. So the output lux obtained from one fiber varies between 1.5 to 7 lux respectively from its minimum and maximum values. Generally, a CFL tubelight of 40 Watts is used for lighting interior spaces with a lux of 100 to 300 lux in the building. For 8 hours of use in a day one CFL tubelight can consumes about $0.32 \mathrm{kwh}$ of energy, so annually it consumes about $116.8 \mathrm{kwh} /$ day/year of energy. The electricity required for lighting the tubelight basically comes from burning coal, which produces carbon dioxide as a byproduct and released in the atmosphere. An average $\mathrm{CO}_{2}$ of 870 grams is emitted for generating $1 \mathrm{kwh}$ of energy by burning coal, so by using a CFL tubelight for lighting 8 hours a day for 1 year generates about $101.61 \mathrm{~kg}$ of $\mathrm{CO}_{2}$ over the year. If daylighting system is used for lighting the interior spaces or if one CFL tubelight could be replaced by this system, then it could save $101.61 \mathrm{~kg}$ of $\mathrm{CO}_{2}$ every year which is released by burning coal to generate electricity. Also the system uses natural sunlight for lighting which falls in the visible spectrum that is excellently perceived by the human eyes, and studies have proved that natural sunlight provides additional physiological and psychological benefits to human beings.

The temperature measurements taken at the input and output end of the optical fiber throughout the testing period yielded a maximum temperature of close to $60{ }^{\circ} \mathrm{C}$ at input end and about $50{ }^{\circ} \mathrm{C}$ at the output end. From these results it can be concluded that the temperature during the testing period did not exceed the permissible operating temperature of the optical fibers. On comparison of the mean temperature with the output temperature of the fiber optical bundle, it was noticed that there was a difference of 5 to $10^{\circ} \mathrm{C}$ at the output end as compared to the input end. From this observation it can be concluded that the heat transfer is inhibited through the fibers and hence the output end of the fiber optical bundle remains cooler then the input end.

Table 6 Illumination level needed for interior spaces in different buildings. $(31,32)$

\begin{tabular}{|c|c|c|}
\hline Locations & Interior Space & Lux \\
\hline \multirow{2}{*}{ Office } & $\begin{array}{c}\text { Conference, Reception } \\
\text { room. }\end{array}$ & $200-750$ \\
\hline \multirow{3}{*}{ Factory } & $\begin{array}{c}\text { Packing work, Entrance } \\
\text { passage }\end{array}$ & $150-300$ \\
\cline { 2 - 3 } & $\begin{array}{c}\text { Visual work at production } \\
\text { line }\end{array}$ & $300-750$ \\
\hline \multirow{2}{*}{ Hotel } & Public room, Cloakroom & $100-200$ \\
\cline { 2 - 3 } & Reception, Cashier & $200-1000$ \\
\hline \multirow{2}{*}{ Hospital } & Sickroom, Warehouse & $100-200$ \\
\cline { 2 - 3 } & Medical Examination room & $300-750$ \\
\hline \multirow{3}{*}{ School } & Auditorium, Indoor & $100-300$ \\
\cline { 2 - 3 } & Gymnasium & $200-750$ \\
\cline { 2 - 3 } & Class room & $150-200$ \\
\hline
\end{tabular}

\section{REFERENCES}

[1] Science Learning

$\mathrm{Hub}$ (https://www.sciencelearn.org.nz/resources/1572what-is-energy)

[2] Solar and Sustainable Energy (https://ag.tennessee.edu/solar/Pages/What\%20Is\% 20Solar\%20Energy/ Sun\%27s\%20Energy.aspx)

[3] Survey of renewable energy in India. TERI (Tata Energy Research Institute), New Delhi; 2001.

[4] Muneer T, Asif M, Munawwar S.,(2005), "Sustainable production of solar electricity with particular reference to the Indian economy", Renewable and Sustainable Energy Reviews, Vol. 9(5), pp. 444-473

[5] Latitudinal and Longitudinal extents of India, Indian States \& Cities (http://www.quickgs.com/latitudinal-and longitudinal-extents-of-india-indian-states-andcities/)

[6] Atul Sharma, (2011), "A comprehensive study of solar power in India and World", Renewable and Sustainable Energy Reviews, Vol.15 , pp 17671776 
[7] Dr. Satish Kumar, USAID ECO - III Project, 2011; Energy Use in commercial buildings - Key findings from the national benchmarking study. USAID INDIA

[8] Climate Works Foundation, 2010, (www.climateworks.org)

[9] National Planning Commission Report, 2011

[10]Lighting Energy in Buildings (http://www.lightinglab.fi/IEAAnnex45/guidebook /2_lighting\%20energy\%20in\%20buildings.pdf)

[11]Kok-Keong Chong , Onubogu Nneka Obianuju, Tiong-Keat Yew, Chee-Woon Wong and WoeiChong Tan (2017), “ Design and construction of active daylighting system using two-stage nonimaging solar concentrator", Applied Energy, Vol. 207, pp. 45-60.

[12] International Energy Agency (IEA). Light's labour's lost: policies for energy efficient lighting. France: IEA Publications; 2006.

[13] Baggini A, Sumper A. Electrical energy efficiency: technologies and applications. United Kingdom: John Wiley and Sons; 2012.

[14] International Energy Agency (IEA). 25 Energy policy recommendations. France; 2011

[15]Climate Change : Atmospheric Carbon Dioxide ((https://www.climate.gov/newsfeatures/understan ding-climate/climate-change-atmospheric-carbondioxide)

[16] H. Poisel, K. Hofbeck, M. Bloos, M. Lippenberger, S. Schuetz and A. Kist (2012), "Sollektor: progress in fiber optic daylighting”, Proc. SPIE 8485, Nonimaging Optics : Efficient Design for Illumination and Solar Concentration IX, 84850K

[17] The Dark Side of LED Bulbs (https://www.scientificamerican.com/article/ledlightbulb-concerns/)

[18] Stack Exchange (https://astronomy.stackexchange.com/questions/2 1478/in-a-reflecting-telescope-cassegrain-is-therea-difference-between-using-a-co)

[19] Google Earth (https://earth.google.com/web/search/Pillai+HOC+ Educational+Campus,+HOC+Colony,+Rasayani,+ Maharashtra/@18.89289524,73.17692593,18.0751 7996a,663.11895171d,35y,0h,6.58500684t,0r/data=CigiJgokCTDngXSVnDNAETDngXSVn DPAGYxmRxtl1D9AIb75aergPFHA)

[20]Lei li, Juntao Wang, Zhuodong Yang, Geng Luo, Kai Tong, Jin Zhao and Jifeng Song (2018), “An optical fiber daylighting system with large Fresnel lens”,Energy Procedia, Vol. 152 , pp. 342- 347.

[21] Kok-Keong Chong and Onubogu Nneka Obianuju (2017), "High acceptance angle optical fiber based daylighting system using two-stage reflective nonimaging dish concentrator", Energy Procedia, Vol. 105 , pp. $498-504$.
[22] Ravi Gorthala, Meg Tidd and Sean Lawless (2017), "Design and development of a faceted secondary concentrator for a fiber-optic hybrid solar lighting system”, Solar Energy, Vol. 157, pp. 629-640.

[23] Yuexia Lv, Longyu Xia, Jinyue Yan and Jinpeng Bi (2018), "Design of a Hybrid Fiber Optic Daylighting and PV Solar Lighting System", Energy Procedia, Vol. 145, pp. 586-591.

[24] Georgios E. Arnaoutakis, Jose Marques-Hueso, Tapas K. Mallick and Bryce S. Richards (2013), "Coupling of sunlight into optical fibres and spectral dependence for solar energy applications", Solar Energy, Vol. 93 , pp. 235-243.

[25] Hyun Joo Han, Saffa B. Riffat, Sang Hoon Lim and Seung Jin Oh (2013), "Fiber optic solar lighting: Functional competitiveness and potential", Solar Energy, Vol. 94 , pp. 86-101.

[26] Jifeng Song, Zhou Jin, Yong Zhu, Zili Zhou and Yongping Yang (2015), "Development of a fiber daylighting system based on the parallel mechanism and direct focus detection", Solar Energy, Vol. 115, pp. 484-493.

[27] M. Rahou, A. Mojiri, G. Rosengarten and J. Andrews (2016), "Optical design of a Fresnel concentrating solar system for direct transmission of radiation through an optical fibre bundle", Solar Energy, Vol. 124, pp. 15-25.

[28]Zhiping Yang, Lei Li, JunTao Wang, Wenmo Wang and Jifeng Song (2019), "Realization of high flux daylighting via optical fibers using large Fresnel lens", Solar Energy , Vol. 183 , pp. 204-211.

[29] Schlegel G., Burkholder F., Klein S., Beckman W., Wood B and Muhs J. (2004), "Analysis of full spectrum hybrid lighting system", Solar Energy, Vol. 76(4), pp. 359-68.

[30] Hirota Y, Ogino T, Watanabe Y and Oshima M. (2005), "On the energy effic1030iency of a prototype hybrid daylighting system", Solar Energy, Vol. 79, pp. 56-64.

[31] www.docplayer.net

[32] www.dilog.co.uk 